http://dx.doi.org/10.18232/20073496.1220

Artículos

\title{
La electrificación industrial en Chile: 1895-1955
}

\section{Industrial electrification in Chile: 1895-1955}

\author{
Martín Garrido-Lepe ${ }^{1}$ * (D) http://orcid.org/0000-0002-0630-5337 \\ ${ }^{1}$ Universitat de Barcelona, Barcelona, España. \\ * Correspondencia: martin.garrido.lepe@gmail.com
}

Resumen. La presente investigación analiza la trayectoria de la electrificación de las industrias chilenas entre 1895 y 1955, como ejemplo de aquellos países periféricos de industrialización tardía que no lograron insertarse al grupo de países de ingreso alto. Empleando datos inéditos sobre la potencia mecánica industrial, se sostiene que los trastornos generados por las guerras mundiales provocaron dificultades en el proceso de modernización industrial, motivando un retorno al uso de motores primarios por sobre los eléctricos. Este estudio demuestra que la transición hacia el motor eléctrico no estuvo exenta de conflictos, y que tales problemas pudieron afectar los incrementos de productividad industrial.

Palabras clave: electrificación; modernización; industrialización chilena; transición energética; productividad industrial.

Abstract. This research deals with the electrification trajectory of Chilean industries between 1895 and 1955 , as an example of those peripheral countries of late industrialization that failed to join the group of high-income countries. Using unpublished data on industrial mechanical power, it is argued that the disorders generated by the World Wars caused difficulties in the process of industrial modernization, motivating a return to the use of primary motors over electric ones. This study shows that the transition to the electric motor was not without conflicts and that such problems could have affected the increases in industrial productivity.

Key words: electrification; modernization; Chilean industrialization; energy transition; industrial productivity.

CÓMO CITAR: Garrido-Lepe, M. (2022). La electrificación industrial en Chile: 1895-1955. América Latina en la Historia Económica, 29(2), 1-29. DOI: 10.18232/20073496.1220 
JEL: N66; N76; Q43.

Recibido: 6 de julio de 2020.

Aceptado: 12 de enero de 2021.

Publicado: 8 de diciembre de 2021.

Organismo patrocinador: Este artículo ha sido financiado por la Agencia Nacional de Investigación y Desarrollo (ANID) en el marco del programa Becas Chile, del cual el autor es beneficiario.

Agradecimiento: Se agradecen los comentarios realizados por Marc Badía Miró (Universitat de Barcelona) y de los tres evaluadores anónimos. Todos los déficits persistentes son responsabilidad del autor.

\section{INTRODUCCIÓN}

Muchas han sido las transformaciones que la revolución industrial provocó en las sociedades contemporáneas. Junto al inicio del crecimiento económico moderno, el cambio más significativo se produjo en la estructura del consumo energético (Allen, 2009; Landes, 1979; Smil, 2010; Wrigley, 1993). La adopción de nuevos conversores y nuevas energías modificó la estructura energética de los sectores económicos. El más destacado fue la industria, que sustituyó el trabajo humano por energía mecánica, lo que permitió el tránsito hacia nuevas y potentes máquinas a vapor. Estos motores accionaban el movimiento fuera de las fábricas para luego trasmitirlo, empleando ejes y poleas, hasta su interior. La incorporación del motor eléctrico, desarrollado durante la segunda revolución tecnológica, permitió abandonar el engorroso e ineficiente sistema de transmisión por ejes y poleas, al incorporar pequeños ejemplares de este nuevo invento con conexiones menos invasivas (Kander, Malamina y Warde, 2013; Smil, 2010). Este proceso de electrificación de la industria permitió importantes incrementos de la productividad del trabajo (Devine, 1983; Ristuccia y Solomou, 2014), además de incentivar la convergencia económica entre las economías de industrialización tardía y los líderes de la revolución industrial (Kander et al., 2013). En el largo plazo, el motor eléctrico fue responsable de sucesivas transiciones energéticas (O’Connor, 2010).

La electrificación supuso una fase de la modernización industrial en la que la mayor parte de la fuerza motriz se realizaba mediante el uso de motores eléctricos. Este proceso ha sido ampliamente estudiado en Estados Unidos (Devine, 1983; Du Boff, 1966; Goldfarb, 2005; Ristuccia y Solomou, 2014; Schurr, 1984) y en diversos países de ingreso alto. ${ }^{1}$ Sin embargo, poco se ha dicho sobre la modernización industrial en actuales países de ingreso medio y bajo. ${ }^{2}$ La presente investigación analiza la electrificación de las industrias chilenas, como ejemplo de aquellos países periféricos de industrialización tardía que no lograron insertarse al grupo de países de ingreso alto.

El estudio del caso chileno demuestra que la transición hacia el motor eléctrico que siguieron las economías de ingreso alto no puede considerarse como un patrón generalizado en el mundo. Con datos inéditos sobre la potencia mecánica industrial, se sostiene que la electrificación de la

${ }^{1}$ La modernización industrial ha sido estudiada en Finlandia (Myllyntaus, 1990); Noruega (Venneslan, 2009); Suecia (Schön, 2000); Japón (Minami, 1977); Italia (Bardini, 1997) y Portugal (Teives y Sharp, 2019); así como en un grupo de países europeos en perspectiva comparada (Betrán, 2005).

${ }^{2}$ Según Foxley (2012), el Fondo Monetario Internacional situó el umbral para entrar en la categoría de economías de ingreso alto en 22000 dólares por habitante en 2010, lo que considera también la diversificación de exportaciones e integración en el sistema financiero global. En la categoría de ingreso medio (9000 y 22000 dólares por habitante en 2010) incluye a Argentina, Brasil, Colombia, Costa Rica, Chile, México, Perú, Uruguay y Venezuela, además de algunas economías del este de Europa y de Asia. 
industria chilena se interrumpió durante el periodo de entreguerras, destacándose por un retroceso en el uso de la potencia de los motores eléctricos. Al inicio de la Gran Guerra, los indicadores de electrificación industrial situaban a Chile a la par de los países de ingreso alto. Sin embargo, al iniciarse la segunda guerra mundial, la industria chilena mostraba un atraso relativamente significativo respecto a estas economías. ${ }^{3}$ ¿Qué provocó este atraso? La hipótesis que se sugiere es que las dificultades para importar bienes de capital, provocadas por las guerras mundiales, motivaron un retorno al uso de motores a vapor propios de una etapa anterior en la secuencia de modernización. Dicho retroceso en la transición hacia el motor eléctrico pudo tener consecuencias negativas sobre la productividad de la industria.

Para valorar el grado de modernización industrial se emplea el indicador de electromecanización industrial, comprendido como la "relación entre la potencia de los motores eléctricos respecto a la potencia total de los motores" en la industria (Comisión Económica para América Latina y el Caribe, 1956, p. 48). Para su análisis, se ofrecen datos de diversos países de ingreso alto y países latinoamericanos entre 1895 y 1955, permitiéndonos evaluar la modernización industrial en perspectiva comparada y en el largo plazo. De igual forma, se analiza la producción por obrero de las industrias chilenas, se emplean datos contenidos en los anuarios estadísticos de Chile, referente a la cantidad de operarios y empleados por sector industrial, así como la producción anual de cada sector.

El periodo analizado se inicia en 1895, dos años antes de la construcción de la primera central de generación eléctrica en Chile, es decir, cuando toda la potencia industrial era movilizada por motores primarios. ${ }^{4}$ El estudio finaliza en 1955, cuando los conflictos derivados de la segunda guerra mundial ya estaban superados, y cuando se finalizó la primera etapa del Plan de Electrificación Nacional, llevado a cabo por la Empresa Nacional de Electricidad S. A. (EndEsA).

Este estudio es relevante para aclarar ciertas dudas sobre el crecimiento industrial posterior a la primera guerra mundial (Ducoing y Badía-Miró, 2013). En este caso, se trata de analizar cuáles eran las características de la industria temprana en Chile, y de qué forma condicionaron el desarrollo del proceso de industrialización dirigida por el Estado (IDE). ${ }^{5}$ La historiografía chilena ha señalado la importancia del periodo de entreguerras como una etapa significativa del crecimiento industrial (Cariola y Sunkel, 1991; Muñoz, 1968; Sunkel, 2011) e incluso de cambio estructural en el crecimiento económico (Couyoumdjian et al., 2020) e industrial (Palma, 1984); ${ }^{6}$ sin embargo,

${ }^{3}$ En 1940, la electromecanización de la industria chilena rozaba $61 \%$, mientras que las economías de ingreso alto promediaban $82 \%$ (véase cuadro 1 ).

${ }^{4}$ Las primeras centrales generadoras en Chile fueron la Central Hidroeléctrica Chivilingo (1897) y la Central Termoeléctrica Mapocho (1900), instaladas en Lota y Santiago, respectivamente. El mismo año 1897, pero esta vez en el extremo sur, se fundó la Compañía de Luz Eléctrica de Punta Arenas, que electrificó la iluminación de dicha ciudad en 1898. Chivilingo fue la primera central hidroeléctrica de Sudamérica, y tuvo por objetivo abastecer de electricidad las labores desarrolladas en la mina de carbón de Lota, ubicada a aprox. $500 \mathrm{~km}$. al sur de Santiago. En el caso de la Central Mapocho, fue construida por la empresa británica The Chilean Electric Tramway and Light Company, fundada en 1899. Su principal objetivo fue, además de iluminar las calles de la capital, electrificar los nuevos tranvías eléctricos que reemplazaban a los de "sangre", y que comenzaron a circular en Santiago el año 1900. Sobre los inicios de la electrificación en Chile, véase Yáñez (2017a).

${ }^{5}$ Según Bértola y Ocampo (2010, p. 94), los logros, límites y características del desarrollo de esta "industria temprana" condicionó la reacción de las economías latinoamericanas durante el periodo de la industrialización dirigida por el Estado.

${ }^{6} \mathrm{Al}$ contrario, Badía-Miró y Ducoing (2014) señalan que la industria chilena no fue un líder durante el ciclo del salitre, y que no era capaz de transformar el país en una economía moderna. Según los autores, los ciclos de recursos naturales afectaron a la economía chilena, pero sin impulsar un cambio estructural en la economía. 
poco se ha dicho sobre la modernización industrial durante el periodo de entreguerras. Conocer los conflictos que atravesó la industria para modernizarse puede ayudar a entender los problemas a los que se enfrentó el Estado durante la industrialización dirigida (ca. 1930-1980).

El artículo se compone de seis apartados. Luego de esta introducción, la sección dos analiza el proceso de electrificación industrial en el mundo. La sección tres presenta y compara nuestra evidencia sobre la electrificación industrial en Chile con la de países de ingreso alto, además de analizar las consecuencias que tuvieron las guerras mundiales en la importación de bienes de capital. La sección cuatro analiza el crecimiento de la productividad industrial y las consecuencias que pudo tener la electrificación de la industria por sector. La sección cinco caracteriza la electrificación de las industrias chilenas, analizando su estructura y la trayectoria según el sector, y, por último, la sección seis presenta las conclusiones.

\section{LA ELECTRIFICACIÓN INDUSTRIAL EN PERSPECTIVA HISTÓRICA}

Los inicios de la electrificación industrial se remontan a fines del siglo XIx, cuando la bombilla eléctrica inició la sustitución de la iluminación a gas en gran parte de las instalaciones industriales (Fouquet, 2010; Smil, 2010). Pese a los beneficios que ello supuso para la visibilidad y seguridad de los trabajadores, el impacto de la electricidad no habría sido decisivo sino hasta su aplicación en la potencia mecánica, mediante la introducción del motor eléctrico.

El análisis de la electrificación industrial en países de ingreso alto está bastante avanzado por parte de la historiografía europea y estadunidense. En estos países, la electrificación de la potencia industrial se intensificó durante la primera guerra mundial, cuando las restricciones comerciales que produjo el conflicto bélico provocaron un incremento en los precios relativos del carbón importado, incentivando el desarrollo de la hidroelectricidad (Fouquet, 2016; Betrán, 2005). Al mismo tiempo, se produjo una reducción de los precios de la electricidad, influenciada por factores técnicos ${ }^{7}$ e institucionales. ${ }^{8}$

Además de un cambio en los precios relativos de las energías, la electrificación industrial fue motivada por una reducción en los costos de producción. Este fue el caso de la industria estadunidense, en la que la escasez de mano de obra no calificada incrementó los salarios, induciendo a la mecanización de la industria (Oshima, 1984). Según Woolf (1984), el principal ahorro de la electrificación industrial se consiguió en el factor trabajo. Por otro lado, la adopción del motor eléctrico en la industria de este país permitió una reorganización interna de la producción industrial, provocando incrementos en la productividad del trabajo (Devine, 1983), a la vez que una reducción de la intensidad del capital (Du Boff, 1966; Oshima, 1984), reducción de la intensidad energética (Schurr, 1984; Smil, 2004), y una reducción del capital inicial necesario para la instalación de nuevos establecimientos (Du Boff, 1966; Goldfarb, 2005; Ristuccia y Solomou, 2014).

$\mathrm{Al}$ analizar la electrificación industrial en perspectiva comparada, Ristuccia y Solomou (2014) demuestran que los incrementos en productividad derivados de la adopción de la electricidad fueron más significativos en Estados Unidos que en Reino Unido, Japón y Alemania, situación que también confirmó Minami (1977). Por otro lado, dicho incremento de productividad derivada

${ }^{7}$ El incremento de la eficiencia derivada del cambio técnico y la introducción de la corriente alterna, permitieron reducir los costos de generación, facilitando la reducción de los precios de la electricidad (Millward, 2005).

${ }^{8}$ La regulación de las tarifas eléctricas durante las primeras décadas del siglo xx permitió la reducción de los precios de la electricidad (David, 1990). 
de la electrificación también se observó en diversos países de industrialización tardía, como Suecia (Schön, 2000), Noruega (Venneslan, 2009), Finlandia (Myllyntaus, 1990) y España (Antolín, 1988; Sudrià, 1994).

A diferencia del análisis de la electrificación en países de ingreso alto, el análisis de esta situación en actuales países de ingreso medio y bajo ha estado casi ausente en la historiografía. Para estos casos, sólo contamos con indicaciones generales realizadas por la Comisión Económica para América Latina y el Caribe (CEPAL) a mediados del siglo xx. Según la cePal (1956, p. 47), en los países "subdesarrollados" faltaron por realizarse algunas de las etapas de la modernización industrial, conviviendo un grupo de nuevas industrias (mecanizadas y electrificadas) con otras industrias antiguas, caracterizadas por el uso de máquinas en proceso de obsolescencia tecnológica.

En la región, el enfoque de este análisis cae bajo el estudio de la modernización industrial, sin ahondar en la importancia del motor eléctrico ni en la electrificación industrial. Sobre la modernización de la industria latinoamericana, se ha señalado que la falta de encadenamientos por parte del sector exportador, durante la Primera Globalización Económica (1870-1914), limitó el desarrollo de una industria manufacturera moderna, debido a factores entre los que destaca la inexistencia de fuentes de energía (Bulmer-Thomas, 2003). Pese a ello, la industrialización en las economías líderes de América Latina se encontraba más avanzada que en otras partes de la periferia económica, con un rápido crecimiento industrial entre 1900 y 1913 (Gómez-Galvarriato y Williamson, 2009). Este argumento también es respaldado desde el análisis del consumo de energías primarias, principalmente de carbón mineral. De acuerdo con esta visión, entre 1890 y 1925, las economías latinoamericanas presentaron experiencias heterogéneas en su proceso de modernización, siendo Argentina, Chile, Cuba y Uruguay los más destacados de la región (Bertoni y Román, 2013; Rubio et al., 2009; Yáñez et al, 2013).

Un gran cambio en la modernización industrial lo supuso la primera guerra mundial. ${ }^{9}$ Este conflicto provocó el colapso del modelo primario exportador que caracterizaba a la región, promoviendo el desarrollo manufacturero como alternativa para estimular el crecimiento económico. En este sentido, las restricciones comerciales fomentaron una industrialización temprana en algunos países de la región, destacándose sólo Brasil, Chile y Perú por el crecimiento experimentado de la producción industrial (Bulmer-Thomas, 2003, pp. 180-188).

En el caso chileno, las restricciones comerciales ocasionadas por el conflicto bélico impidieron continuar con el ritmo normal de importaciones de bienes de consumo durable, intermedios y de capital. Por ello, la industria manufacturera chilena habría aprovechado esta oportunidad, aumentando su producción para llenar los vacíos existentes (Palma, 1984). Sin embargo, este impulso no habría perdurado durante la posguerra. Después de la Gran Guerra, la industria chilena tardó casi una década en alcanzar los niveles de crecimiento previos al conflicto (Ducoing y Badía-Miró, 2013). El mismo efecto se observó en la participación relativa de la industria en la formación bruta de capital en maquinaria, que había sido destacada antes de la guerra, pero que se redujo considerablemente entre 1913 y $1938 .^{10}$

${ }^{9}$ La Gran Guerra también provocó cambios en la matriz energética de las economías latinoamericanas. El deterioro del comercio exterior redujo las importaciones de carbón, encareciendo los precios de la energía primaria (Badía-Miró y Carreras-Marín, 2008), situación que fomentó la transición energética de los combustibles fósiles (Rubio y Folchi, 2012; Rubio, 2019). La gran minería chilena fue un gran protagonista de esta transición (Garrido-Lepe, 2018).

${ }^{10}$ Entre 1895 y 1912, el porcentaje de la maquinaria industrial sobre el total de la formación bruta de capital en maquinaria promedió 38.58 \%, reduciéndose a 25.14 \% entre 1913 y 1938 (Ducoing, 2012). 
El argumento de Ducoing y Badía-Miró (2013) refuerza el de Ortega (1992), quien da cuenta de las dificultades que experimentó la industria entre el fin de la guerra y la crisis de 1929. Según este autor, terminada la guerra, la economía y en particular el sector exportador, vivió un periodo de inestabilidad prolongada, que acabaría con la crisis de la gran depresión de 1929. El sector industrial también fue afectado por estas crisis, demostrando su sensibilidad frente al comportamiento del comercio exterior. En este sentido, la producción industrial cayó entre 1918 y 1919 , con mayor declinación entre 1920 y 1922. Su recuperación fue vigorosa hasta 1923, con máxima expansión hasta 1925; sin embargo, la recesión externa de ese año ocasionó una desaceleración del crecimiento industrial, que sólo se recuperó en 1927, hasta colapsar definitivamente con la crisis de 1929 (Ortega, 1992, p. 234).

Los trastornos que vivió la industria chilena durante la década de 1920 también han sido detectados desde la composición de su fuerza laboral. En este sentido, Veneros y Ortega (2011) observan que, en el periodo de entreguerras, el empleo industrial habría mostrado un cambio sustancial en su estructura, manifestada en una reducción significativa del empleo infantil y menor intensidad del femenino. Tal reducción podría indicar un proceso de modernización como el que analizamos en esta investigación, y que estaría protagonizada por el motor eléctrico como sustituto del factor trabajo.

La crisis de la gran depresión económica marcó un nuevo cambio en la trayectoria industrial chilena y latinoamericana, al estimular la transformación de la industria manufacturera al incrementar el peso de las industrias de bienes intermedios y de capital (Durán, Musacchio y Della Paolera, 2017). ${ }^{11}$ Según Bértola (2011), el periodo comprendido entre 1929 y 1945 fue, para América Latina, un periodo de transición entre el modelo primario-exportador y el modelo de industrialización dirigida por el Estado. Luego de este periodo de transición se produciría la “cristalización" del modelo de industrialización dirigida por el Estado entre 1945 y $1973 .{ }^{12}$ Todo este proceso estuvo vinculado estrechamente con la modernización energética. A medida que la industria avanzaba de etapas, también lo hacían sus necesidades energéticas. En este sentido, la expansión de la industria no fue un proceso exclusivamente cuantitativo, sino también cualitativo.

En Chile, el proceso de industrialización ha sido dividido en dos partes por Ffrench-Davis, Muñoz, Benavente y Crespi (2003): uno entre fines de la década de 1930 y 1973, caracterizado por intentar desarrollar un nuevo tejido industrial que no existía; y la segunda parte, entre 1973 y 1990, caracterizada por un abandono del proyecto de industrialización y la puesta en marcha de un proyecto de economía abierta, basado en los incentivos que el mercado ofrecía al sector privado. Según ellos, durante la primera etapa (1930-1973), las industrias gozarían de una protección natural producto de la crisis de la gran depresión y de la segunda guerra mundial, que habrían incentivado el crecimiento de este sector.

Sin embargo, la segunda guerra mundial también representó problemas para la industrialización del país. Las restricciones comerciales que provocó la guerra impidieron que los planes de industrialización pudieran implementarse en su totalidad, en particular debido a las dificultades

${ }^{11}$ Como señaló Hirschman (1968), no importa cuál fuese el impulso original, la industrialización por sustitución de importaciones partió predominantemente con las manufacturas de bienes de consumo final que eran previamente importados, y luego se movió hacia las etapas elevadas de la manufactura, es decir, hacia los bienes intermedios y maquinaria, mediante efectos de encadenamiento hacia atrás.

${ }^{12}$ Según el autor, el modelo de industrialización dirigida por el Estado se caracterizó por focalizarse en la industrialización como eje del desarrollo; ampliar la esfera de acción del Estado en materia económica y social, y orientar la producción hacia el mercado interno (Bértola, 2011, p. 258). 
para importar bienes de capital. Sólo cuando el conflicto finalizó, la modernización industrial pudo continuar (Sunkel, 2011). Las dificultades para avanzar con la modernización se manifestaron en una prolongación del consumo de carbón mineral en la industria. Sólo cuando la importación de bienes de capital se recuperó, la industria pudo abandonar el consumo de carbón, transitando al consumo de electricidad (Yáñez y Garrido-Lepe, 2015).

El proceso de industrialización dirigida por el Estado estuvo estrechamente vinculado con la electrificación nacional. Desde 1939, el Estado se hizo partícipe activo en la conducción de este proceso, primero mediante el trabajo de la Corporación de Fomento de la Producción (Corfo) y, desde 1943, mediante la labor de la Empresa Nacional de Electricidad S. A. (EnDESA).

Con base en los datos de la ENDESA $(1965,1986)$, observamos que el crecimiento de la capacidad instalada de generación eléctrica en Chile incrementó sustancialmente su crecimiento con el trabajo de la ENDESA. En términos concretos, la capacidad instalada total en Chile aumentó de 301 MW a 529 MW entre 1930 y 1945, lo que marcó un crecimiento anual de $3.8 \%$. Hacia 1960, la capacidad instalada total ascendía a $1.142 \mathrm{MW}$, es decir, un crecimiento de $5.26 \%$ al año entre 1945 y 1960. De los 613 MW agregados en esos quince años, 393 MW correspondían a las centrales de generación construidas por la ENDESA. Este incremento de la capacidad instalada revela las necesidades energéticas que suponía la modernización del país, y particularmente de la industria manufacturera.

Nazer y Llorca-Jaña (2020) destacan el trabajo de la ENDESA como un caso exitoso de electrificación dirigida por el Estado. Por otro lado, Yáñez (2017b) destaca la importancia de la intervención estatal en el proceso de electrificación durante el siglo xx y concluye que fueron razones económicas (no políticas ni sociológicas) las que llevaron al Estado a asumir el orden en la industria eléctrica de la década de 1940. El mismo Yáñez (2019) planteó que la experiencia que el sector público acumuló con la construcción y administración de los ferrocarriles del Estado sirvió para el desarrollo de la electrificación nacional de mediados del siglo xx.

Sin embargo, la segunda guerra mundial también implicó dificultades para el desarrollo de la labor de la ENDESA, lo que prácticamente imposibilitó conseguir de manera simultánea todos los equipos que las instalaciones requerían. Por ello, los esfuerzos se concentraron en construir la central hidroeléctrica Pilmaiquén, en las cercanías de Osorno, la más sencilla de las tres que había propuesto Corfo en 1939 (Corfo, 1939). Esta pudo ponerse en servicio en 1944, con dos unidades de 4.5 MW. Posteriormente, en 1948, pudieron entrar en funcionamiento las centrales hidroeléctricas Sauzal (75 MW), al sur de Santiago, y la primera etapa de la central hidroeléctrica Abanico (86 MW), en las cercanías de Concepción. Por último, en 1955, con la construcción de la Central Cipreses (101 MW) en las cercanías de Santiago, se dio por finalizada la primera etapa del Plan de Electrificación del País, que estaba previsto para 1950 (EndEsA, 1993, p. 55).

$\mathrm{El}$ análisis realizado hasta ahora muestra la importancia que merece estudiar el impacto de las guerras mundiales en la historia de la electrificación industrial. En este sentido, desde principios del siglo xx, la industria chilena presentaba un grado de modernización avanzado, comparable con actuales países de ingreso alto. Sin embargo, los obstáculos del periodo de entreguerras la sumieron en un atraso relativo de 20 a 25 años respecto a los países líderes. La presente investigación se plantea analizar las causas de este atraso relativo y sus consecuencias para la productividad de la industria chilena. Para ello, la siguiente sección analiza el principal indicador para medir la electrificación industrial: el coeficiente de electromecanización. 


\section{LA ELECTRIFICACIÓN INDUSTRIAL EN PERSPECTIVA COMPARADA}

Como se señaló, para medir el grado de electrificación de la potencia mecánica utilizada en las industrias, emplearemos el coeficiente de electromecanización. El cuadro 1 muestra este indicador para nueve países de ingreso alto y seis latinoamericanos, para diversos años entre 1895 y 1955. El primer grupo lo componen Alemania, Canadá, Dinamarca, Finlandia, Japón, Noruega, Suecia, Reino Unido (UK) y Estados Unidos (EUA). El grupo de los países latinoamericanos lo componen Argentina, Brasil, Chile, Colombia, México y Uruguay. Cabe señalar que, como nuestros datos son mayores para Chile, Estados Unidos, Japón y Suecia, la mayor parte del análisis recae en la comparación de la electrificación de la industria de estos países.

Antes de la primera guerra mundial, todas las economías presentaban una electromecanización industrial menor a $30 \%$, con pequeñas diferencias entre ellas. Los datos del cuadro 1 muestran que, durante la primera década del siglo xx, en Alemania, Canadá, Dinamarca, Finlandia, Japón, Noruega, Suecia, Reino Unido, Estados Unidos, Chile, Argentina, Brasil, Colombia, México y Uruguay se gestaba un proceso de modernización incipiente. Para el caso chileno, en 1895, ninguna de las industrias que respondió a la encuesta formulada por la Sociedad de Fomento Fabril (Sofofa) utilizaban motores eléctricos. Sí, en cambio, existen muchas industrias con iluminación eléctrica, por lo que la tecnología de generación eléctrica no les era desconocida. De hecho, ese mismo año, el ingeniero Enrique Vergara-Montt pronunciaba un discurso que resaltaba los beneficios de la electrificación industrial en otras latitudes, y que fue publicado en la revista Anales del Instituto de Ingenieros de Chile. En dicho documento, el autor no sólo demostraba los beneficios técnicos y económicos de adoptar la tecnología eléctrica, sino que exaltaba el uso de los recursos hidráulicos y minerales del territorio nacional en la generación y transmisión de electricidad (Vergara-Montt, 1895).

Los datos sobre motores eléctricos en Chile sólo se registran por primera vez en $1909,{ }^{13}$ dando cuenta de 422 motores eléctricos en las industrias chilenas, que producían una potencia de 3.645 HP, equivalentes a $10.5 \%$ de toda la potencia industrial. No sabemos con certeza qué ocurrió entre esos años, pues las fuentes revisadas hasta el momento no nos permiten estudiarlo. Lo cierto es que, antes de que la primera guerra mundial estallara, las industrias chilenas ya habían iniciado una incipiente modernización de su producción al incorporar el motor eléctrico, en línea con lo planteado por la historiografía chilena (Cariola y Sunkel, 1991; Kirsch, 1977; Ortega, 1992, 2012; Palma, 1984; Sunkel, 2011).

La modernización de la industria chilena durante la década previa a la primera guerra mundial estuvo en línea con el desarrollo de la electrificación del país. Para esta década, tanto Tafunell (2011) como Yáñez (2017a) destacan el rápido avance de la capacidad instalada de generación eléctrica en Chile. Según Tafunell (2011), la tasa de crecimiento de la importación de material

\footnotetext{
${ }^{13}$ Según el Boletín de la Sociedad de Fomento Fabril (Sofofa, 1901, p. 185), en 1901 se contabilizaban 64 HP en motores eléctricos distribuidos entre siete industrias ubicadas en Santiago. Entre ellas, la imprenta del diario El Mercurio contabilizaba 43 HP. Posteriormente, en 1907, se registra la existencia de motores eléctricos en la Fábrica Nacional de Conservas Alimenticias, cerca de Rancagua (Kirsch, 1977, p. 29). Sin embargo, el autor no menciona su potencia ni fuente de generación. Debido a que la falta de datos y fuentes no nos permite conocer el estado de la electrificación entre 1895 y 1909, la mayor parte del análisis se realiza desde esta fecha en adelante. Sin embargo, la información de la Sofofa (1901) citada previamente nos indica que esta pudo haber comenzado incluso a fines del siglo xIx.
} 
eléctrico en Chile, utilizado como proxy para analizar la electrificación, fue de $29 \%$ al año entre 1901 y 1913. Para Yáñez (2017a), el crecimiento de la capacidad instalada total fue de $24.3 \%$ al año entre 1905 y $1913 .{ }^{14}$

La Gran Guerra marcó un cambio sustancial en la trayectoria de electrificación industrial en los países analizados. Mientras esta se intensificaba en los países de ingreso alto, en Chile se detenía. La electromecanización industrial de los países de ingreso alto creció rápidamente por encima de 50 \% en 1920, y superó el 70 \% justo después de la crisis de la gran depresión. Finalmente, la mayor parte de estas economías registraron cifras superiores a $80 \%$ durante la segunda guerra mundial. Un aspecto destacado de esta trayectoria es que las experiencias de electrificación industrial en países de ingreso alto muestran un comportamiento similar. Es decir, un crecimiento muy lento al comienzo, una fase intermedia de crecimiento acelerado, y una fase final de crecimiento nulo o decrecimiento. Esta última fase se alcanzó al lograr entre 80 \% y 90 \% de la electromecanización industrial, comprendiendo esta cifra como su límite de saturación.

En el caso chileno, la electrificación industrial siguió una tendencia diferente a la de las economías de ingreso alto, específicamente desde la primera guerra mundial. Mientras estas aceleraron su electrificación, las industrias chilenas evidenciaron una interrupción que sólo retomaría su crecimiento una vez finalizado el conflicto. Mientras, en 1909, la electrificación industrial chilena marcaba niveles similares a los de Japón, Suecia y, un poco más lejos, de Estados Unidos y Reino Unido; en 1920, las cuatro economías para las que tenemos datos (Canadá, Estados Unidos, Japón y Suecia) casi duplicaban la cifra chilena, promediando una electrificación de $55 \%$ frente a un $33 \%$ de las industrias chilenas. Como se verá en el siguiente apartado, esta interrupción sería sólo en términos relativos, pues la potencia de los motores eléctricos en la industria aumentó $37.7 \%$ entre 1914 y 1917. En cambio, durante el mismo periodo, la potencia de los motores a vapor lo hizo en 51 por ciento.

Aunque las instituciones pudieron haber limitado el desarrollo de las empresas de electricidad, ello no fue la causa principal de la reducción de la electrificación industrial. El Instituto de Ingenieros fue enfático en criticar la regulación eléctrica que existió hasta 1925. En este caso, nos referimos a las regulaciones de 1904 y 1907, que se limitaban a regular el establecimiento de concesiones a las empresas eléctricas y al uso de cursos de agua, respectivamente. Sobre estas regulaciones, señalan que eran deficientes y hostiles, limitando el desarrollo eléctrico en la industria, y que incluso pareciera que buscaran poner obstáculos al aprovechamiento de las fuentes de energía hidráulica (Instituto de Ingenieros de Chile, 2014). Tal afirmación se basa en que no existía una ley que regulase la transmisión de electricidad.

${ }^{14}$ Las dos décadas previas a la primera guerra mundial vieron nacer las primeras empresas eléctricas en Chile, todas ellas de capital privado. La primera de ellas fue la Compañía de Luz Eléctrica de Punta Arenas, establecida en Punta Arenas en 1897. Le siguió la Chilean Electric Tramway and Light Company y la Compañía Alemana Transatlántica de Electricidad, en 1899 y 1901, respectivamente, ambas con el objetivo de proveer electricidad a la ciudad de Santiago. En 1905 se constituyó la Compañía General de Electricidad Industrial, que buscaba proveer de electricidad a las comunas de Nuñoa y San Bernardo. La siguiente gran oleada de empresas eléctricas se produjo después de la primera guerra mundial, con la creación de la Compañía Nacional de Fuerza Eléctrica, en 1919; la Compañía Eléctrica Chilena, en 1921, como resultado de la fusión entre la Chilean Electric Tramway and Light Company y la Compañía Nacional de Fuerza Eléctrica; y la Sociedad Austral de Electricidad S. A., en 1926. Sobre la temprana expansión de la empresa eléctrica en Chile, véanse Instituto de Ingenieros de Chile (1988); Endesa (1993); Yáñez (2017a); Galaz-Mandakovic (2019) y Folchi, Blanco-Wells y Meier (2019). 


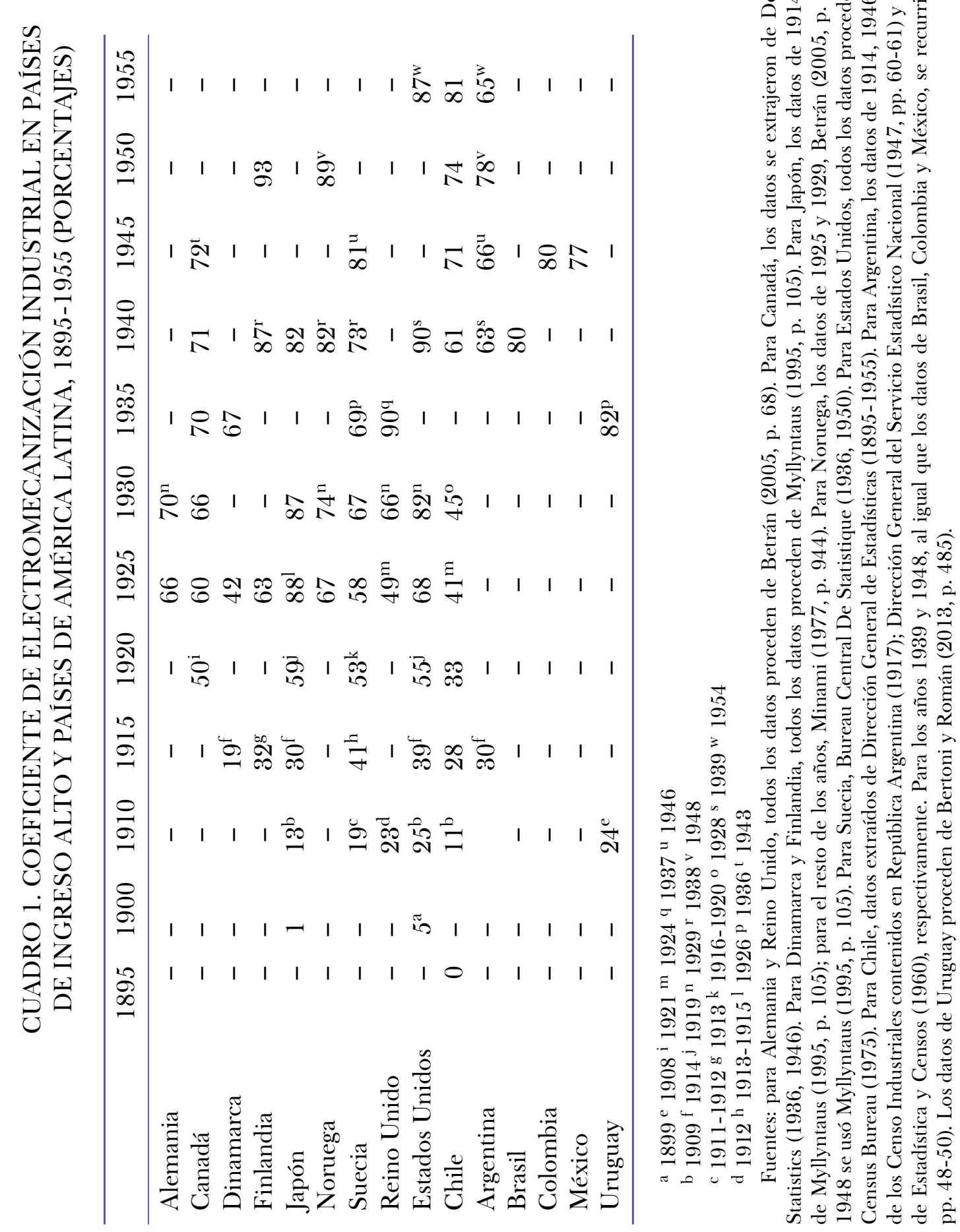

पे

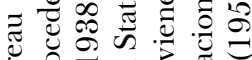

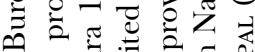

ำ สำ

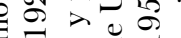

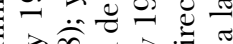

$\lambda \infty=\lambda$.

$\sigma \dot{0} \dot{0} \dot{0}=$

- 10070

के के 00

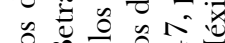

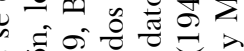

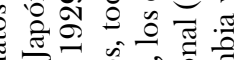

$\pi>\frac{8}{0}$

ㄱำ

$308 \overline{8}$

$\dot{1}$ की

응

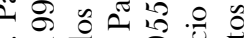

$\infty$ 过

$\therefore$ चै

क

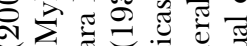

$\exists \div \widetilde{0}$

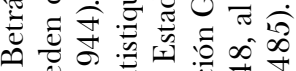

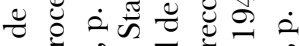

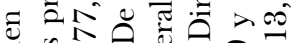

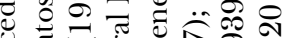

है

की 0 क

$\geqslant$ क

$\infty \begin{aligned} & 0 \\ & 0\end{aligned}$

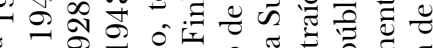

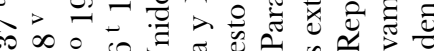
응

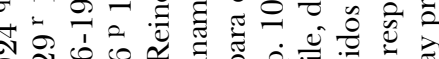

SO

$\Xi=-1 \approx \pi \%$

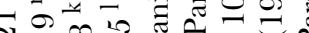

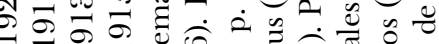

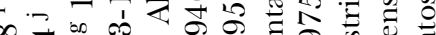

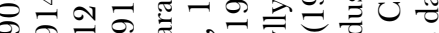

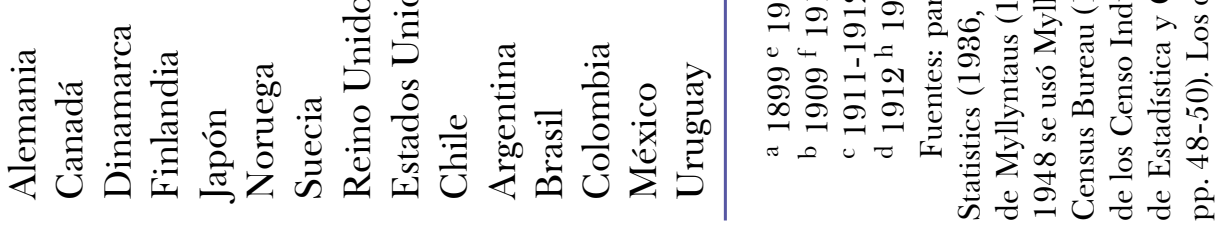


En este caso, las empresas se veían en la obligación de solicitar concesiones que, según la ley de 1904, sólo podían ser otorgadas por diez años, en caso de líneas aéreas, y 20 en caso de líneas subterráneas. Los ingenieros señalan que esos diez años eran muy poco tiempo como para que los empresarios recuperen su inversión. Por ello, no invertían en transmisión.

La regulación eléctrica también comenzaba a tomar relevancia en los proyectos de los sucesivos gobiernos de la época. En 1923, en su discurso ante el Congreso Nacional, el presidente Arturo Alessandri Palma instaba al Congreso a aprobar la nueva ley de Producción y Distribución de Energía Eléctrica, eliminando así las dificultades para el desarrollo de la industria eléctrica en el país (Diarios de Sesiones del Congreso Nacional, 1923, pp. 42-43). Pese a estos impedimentos institucionales, el crecimiento de la capacidad instalada de generación eléctrica siguió siendo vigoroso, tal y como lo demuestran Tafunell (2011) y Yáñez (2017a).

Durante la década de 1920, el crecimiento anual de la electrificación industrial chilena fue similar al de Estados Unidos (4\% y $4.1 \%$ al año, respectivamente), y un poco mayor que el de Japón (3.6\%) y Suecia (2\%). Sin embargo, en 1928, la potencia de los motores eléctricos en las industrias chilenas aún no alcanzaba el 50 \%, cifra que las tres economías previas habían superado entre 1914 y 1919, es decir, más de diez años de atraso.

Nuestros datos señalan que, en 1928, la electromecanización industrial alcanzaba un $45 \%$. Nuestra información no nos permite conocer el desarrollo de la modernización industrial entre esta fecha y 1938, año en que la electromecanización registraba $61 \%$. Sin embargo, es probable que la electromecanización alcanzara niveles superiores a $50 \%$ antes de que los efectos de la crisis de la gran depresión repercutieran en la economía chilena. Este supuesto se sustenta en el elevado gasto en motores entre 1929 y 1931. Por otro lado, podría haber existido un complemento de máquinas a vapor elaborados en Chile. Ortega (1992) señala que, en las últimas décadas del siglo XIX, las industrias chilenas producían e incluso exportaban máquinas a vapor. Estas industrias continuaron con la producción de motores a vapor y máquinas similares en proceso de obsolescencia, incluso durante la década de 1920. Además, según Kirsch (1977, p. 33), antes de la primera guerra mundial existían fundiciones en Chile que podían construir por completo una locomotora. Por otro lado, al analizar el crecimiento de la producción sectorial de la industria entre 1917 y 1927 , el autor destaca el crecimiento del sector de los metales, señalando que la mitad de dicho crecimiento se explica por bienes de capital elaborados internamente. Sin embargo, la falta de mayores evidencias hace que esta afirmación quede exclusivamente en el plano de las hipótesis, siendo su demostración una tarea ajena a los objetivos de esta investigación.

El análisis de la electrificación industrial continúa a fines de la década de 1930. Con base en esos datos podemos saber que, en 1939, cuando CoRfo asumió la dirección de la industrialización, la potencia de los motores eléctricos dominaba en las industrias chilenas, presentando una electromecanización de $60.6 \%$. Esta cifra resulta baja si se la compara con la alcanzada por los países de ingreso alto, que sobrepasaban el $80 \%$. En cambio, la cifra chilena se encontraba en línea con la realidad de Argentina (63\% en 1939). Brasil, México y Uruguay presentaban una situación similar a la de las economías de ingreso alto, con cifras que bordeaban el $80 \%$ durante la segunda guerra mundial. Los datos con los que contamos para el resto de los países de América Latina no nos permiten generalizar sobre la modernización industrial de la región; sin embargo, son un buen ejemplo para comparar las realidades en un momento determinado en que todas estas economías coincidían en la industrialización dirigida por el Estado. 
Pese a presentar un porcentaje de electromecanización industrial menor que las economías de ingreso alto, el crecimiento de este indicador en las industrias chilenas entre 1928 y 1938 fue mayor que en tales países, con $3 \%$ al año. En cambio, el crecimiento de las economías ricas superaba levemente el $1 \%$ al año. En ese momento, el crecimiento de la electrificación de las industrias de países de ingreso alto ya había entrado en una fase de moderación. ${ }^{15}$

El crecimiento de la electrificación industrial chilena hacía suponer una convergencia con las economías de ingreso alto. Sin embargo, el estallido de la segunda guerra mundial volvió a impactar negativamente en la modernización industrial, reduciendo el crecimiento de la electromecanización a $1.7 \%$ al año entre 1939 y 1945 . Al finalizar el conflicto bélico, este proceso volvería a reducir su intensidad, registrando un crecimiento anual de 0.7 \% entre 1945 y 1954.

El comportamiento descrito previamente estaría en línea con la tendencia mostrada por las economías de ingreso alto, de reducir el crecimiento de la electromecanización en las etapas finales de la electrificación industrial. Sin embargo, en el caso chileno, tal reducción se produjo al alcanzar el $70 \%$ de la electromecanización, a diferencia de las economías de ingreso alto, que lo hicieron cuando este indicador registró entre 80 y $90 \%$. Por último, un salto importante ocurriría entre 1954 y 1955, cuando la electromecanización industrial en Chile pasaría de registrar $75.1 \%$ a $80.6 \%$. En este momento, la electrificación de las industrias chilenas acumulaba un atraso relativo de 25 años respecto a la mayoría de los países de ingreso alto.

Como hemos visto, ambas guerras mundiales implicaron periodos de estancamiento o reducción en el crecimiento de la electrificación industrial. En esta investigación se sostiene que los conflictos para electrificar las industrias chilenas durante el periodo de entreguerras estarían vinculados con las crisis internacionales que afectaron el comercio exterior. En este sentido, los mayores impactos de ambas guerras se vieron en la importación de bienes de capital. Palma (1984) manifiesta que, el principal impacto de la primera guerra mundial se observó en la reducción de las importaciones, que afectaron con mayor fuerza a los bienes de capital e intermedios. Del mismo modo, Cabezón (1971) muestra que, durante la segunda guerra mundial, la importación de bienes de capital mostró una reducción significativa en comparación con las décadas previas y posteriores. Estas reducciones afectaron la electromecanización de las industrias chilenas, al complicar el acceso a motores eléctricos, lo que retrasó tanto la modernización de la industria como el crecimiento de su productividad.

Los datos con los que contamos no nos permiten conocer con exactitud cuántos motores se importaban anualmente. Sin embargo, sí podemos conocer el gasto en la importación de motores entre 1908 y 1946 (véase gráfica 1). Según ellos, los efectos de ambas guerras se hicieron sentir en una significativa reducción de la importación de motores, que sólo se superó una vez finalizados ambos conflictos.

En término reales, el gasto en importación de motores cayó 85 \% entre 1910 y 1917. La recuperación no fue sencilla, pues se observan nuevas caídas durante la década de 1920. Sin embargo, lo peor vino después de la crisis de la gran depresión. El gasto en importación de motores en 1932 correspondió a $5 \%$ del total de 1930, sin superar los niveles precrisis hasta finalizada la segunda guerra mundial. Todo parece indicar que esta reducción corresponde a otro más de los efectos de la crisis económica derivada de la gran depresión.

${ }^{15}$ En este mismo periodo, la electromecanización industrial en Suecia creció a $1.1 \%$ al año. Entre 1929 y 1939 , este indicador creció a 0.9 \% al año en Estados Unidos. Japón, en cambio, presentó un crecimiento de - $0.6 \%$ entre 1930 y 1940 . 


\section{GRÁFICA 1. GASTO ANUAL EN IMPORTACIÓN DE MOTORES EN CHILE, 1908-1946 (EN MILLONES DE PESOS DE 2003)}

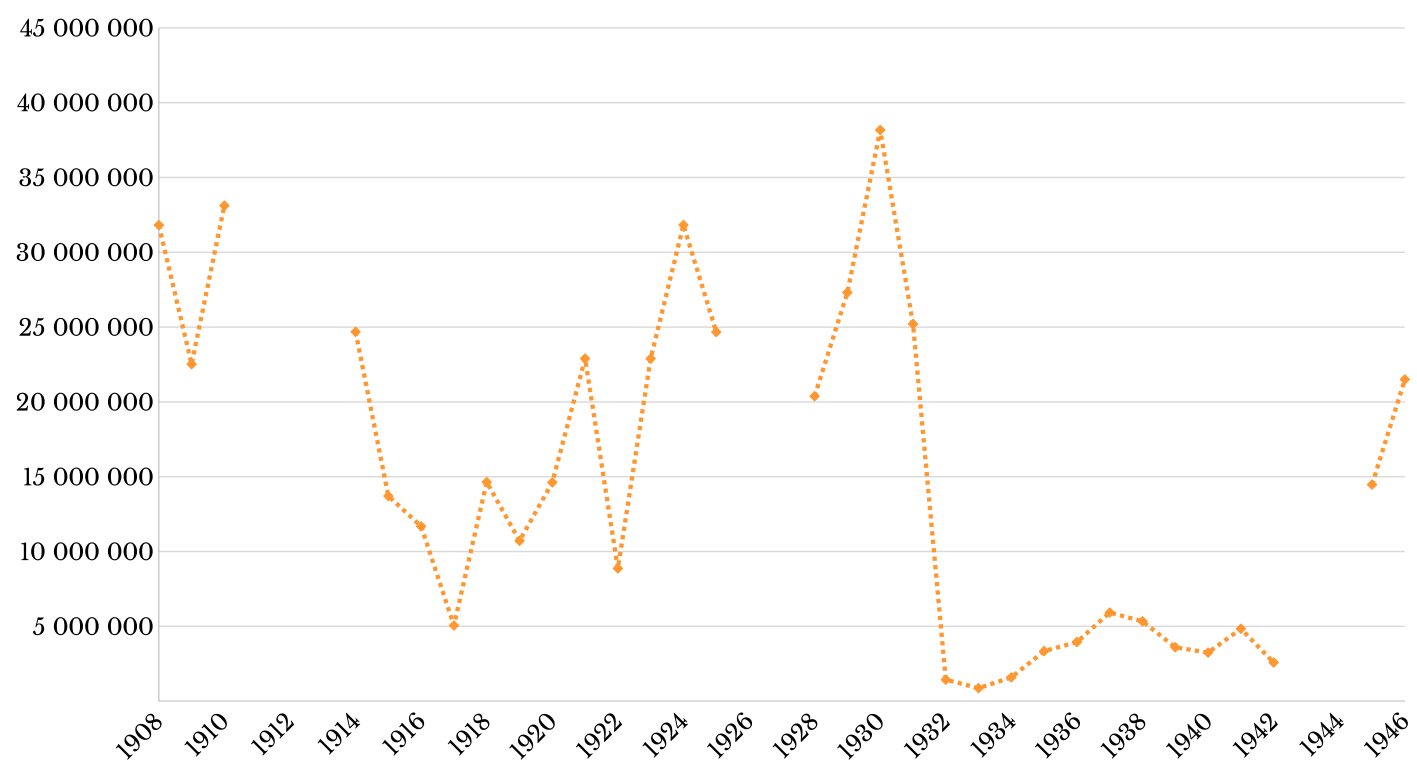

Fuente: Dirección General de Estadísticas (1908-1946).

Hasta 1937 se observa una tímida recuperación, pero la segunda guerra mundial volvería a deprimir el gasto en motores. Una vez finalizado el conflicto, el gasto en importación de motores volvería a niveles precrisis. Nuestros datos demuestran que en 1946 se habían vuelto a alcanzar cifras de gastos similares a los de 1928.

El gasto en importación de motores según el país de procedencia (véase gráfica 2) permite observar las consecuencias de las restricciones comerciales de ambas guerras mundiales. Su principal efecto fue la reducción casi absoluta del gasto en motores provenientes de países europeos. En 1914, la mayor parte del gasto se realizaba en motores procedentes de Reino Unido (42\%), Alemania $(30 \%)$ y Estados Unidos $(21 \%)$. Las restricciones comerciales provocadas por el conflicto se manifestaron en una concentración del gasto en motores procedentes de Estados Unidos, que llegaron a suponer $67 \%$ del gasto total en 1919, complementado con $16 \%$ de motores procedentes de Reino Unido.

La situación de las décadas de 1920 y 1930 se caracterizó por una desaparición del gasto en motores de Reino Unido, que promediaron 22 \% al año entre 1920 y 1929, y sólo 2.8 \% al año entre 1930 y 1939, y una mayor importancia del gasto en motores alemanes, que promediaron $39 \%$ al año entre 1930 y 1939. La segunda guerra mundial volvió a suponer restricciones al comercio exterior con los países europeos, concentrando el gasto en los motores procedentes de Estados Unidos. En este caso, el gasto en motores de este país promedió $72 \%$ entre 1939 y 1945, con un máximo de $94 \%$ en 1945. 


\section{GRÁFICA 2. GASTO EN IMPORTACIÓN DE MOTORES SEGÚN PAÍS DE PROCEDENCIA, 1914-1942 (PORCENTAJES)}

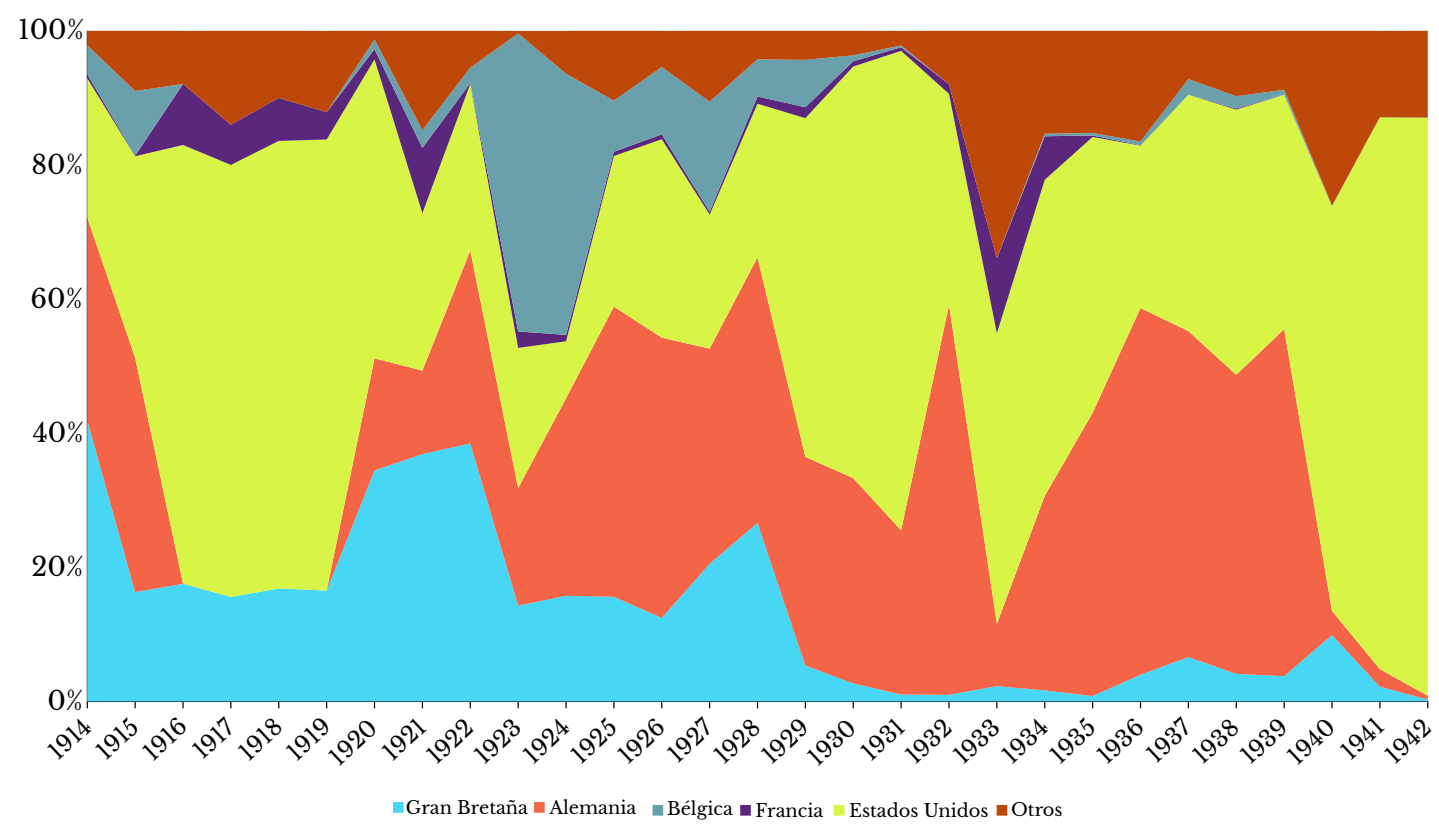

Fuente: Dirección General de Estadística (1914-1942).

El hecho de que la mayor parte del gasto en motores de la década de 1920 se haya realizado en importación de productos alemanes y estadunidenses es significativo, pues nos da indicios de la tendencia que seguía la industria chilena. Durante esta década, la industria alemana y estadunidense se caracterizó por alcanzar niveles de electrificación superiores a $70 \%$, a diferencia de la industria británica, que presentaba un atraso relativo frente a estas dos economías.

\section{LA TRAYECTORIA DE LA PRODUCTIVIDAD INDUSTRIAL EN CHILE}

Entre las consecuencias de la electrificación industrial, tal vez la más estudiada, sea su impacto en la productividad de las industrias. Según Devine (1983), la transición hacia la electrificación provocó ahorros indirectos en los costos de producción industrial. Sin embargo, el autor encuentra un retraso entre la adopción de electricidad y el incremento de la productividad, hasta que $50 \%$ de las máquinas hayan realizado la transición. En Suecia, Enflo, Kander y Schön (2009) detectan que la electricidad tuvo mayor impacto en la productividad de las industrias que la usaron para múltiples propósitos. Al contrario, Ristuccia y Solomou (2014) demuestran que no hubo un incremento generalizado de la productividad derivado de la difusión de la electricidad, sino que estos variaron ampliamente entre los países y las industrias.

En América Latina, entre 1913 y 1919, la productividad del trabajo creció más lentamente en Chile que en casi todos los países de la región, excepto Argentina. Esto se debe a que partía de niveles comparativamente altos, del orden de $42 \%$ de la productividad del trabajo de Estados Unidos. En Argentina la situación era similar, pues partían de 53 \% de la productividad de Estados 
Unidos. Sin embargo, pese a que casi todas las economías de ingreso medio de la región presentaron crecimiento positivo para todo el periodo 1913-1950, la distancia con Estados Unidos, en términos de productividad del trabajo, aumentó (Hofman, 2000).

Según Astorga, Bergés y Fitzgerald (2011, p. 207), en la fase inicial "expansiva” de la industrialización, el empleo crece más rápido y la productividad se expande menos que el producto. En cambio, en la siguiente fase "intensiva" de la industria, el empleo debería crecer más lentamente y la productividad acelerarse. Por otro lado, según tales autores, la productividad industrial en Chile creció mucho más rápido entre 1930 y 1950 que entre 1910 y 1930 . Esto es justamente lo que muestran nuestros datos (véase cuadro 2), que corresponden a la producción total de la industria por operario de cada sector industrial entre 1909 y 1950.

El crecimiento de la producción por trabajador entre 1914 y 1928 fue mucho menor que en el periodo 1938-1950, con $4.7 \%$ y $17.7 \%$ al año, respectivamente. Esta diferencia radica en las dinámicas de expansión de cada etapa. En el primer periodo, el crecimiento de la industria fue "extensivo", aumentando tanto el número de establecimientos, como el número de operarios y de la potencia mecánica. En cambio, desde 1938, la expansión de la industria fue "intensiva", lo que redujo el número de establecimientos mientras incrementaba la potencia de sus motores, pero también el número de operarios. ${ }^{16}$ La historiografía ha elogiado la capacidad de la industria para absorber la mano de obra desde otros sectores (Muñoz, 1968; Sunkel, 2011). Sin embargo, este fenómeno puede ser reinterpretado. Probablemente, y ante la falta de bienes de capital, la industria recurrió al factor trabajo para aumentar su producción, y así impedir un incremento sustancial de la productividad.

Desde el aspecto sectorial, las industrias más productivas eran las de los alimentos, la de productos químicos, la industria del tabaco y la de alcoholes y bebidas. En cambio, las de menor productividad eran las industrias de alfarería, cerámica y vidriería, las de metales y sus manufacturas, las de materiales de construcción y las de confecciones y vestuarios. Este hecho resulta paradójico pues, como se verá más abajo, entre las industrias más productivas se encuentran aquellos sectores que presentaban las peores cifras de electromecanización. En cambio, en el grupo de las industrias de menor productividad, encontramos sectores caracterizados por su elevada electromecanización, como son la industria de alfarería y cerámica, la de confecciones y vestidos y, desde 1920, las de metales y sus manufacturas. Tal vez el único sector en el que existe una relación positiva entre la electromecanización y la productividad del trabajo es en la industria del tabaco, posiblemente por el reducido número de máquinas empleadas. Por lo anterior, pareciera que la electrificación de la fuerza motriz en la industria no se habría hecho sentir inmediatamente en el incremento de la productividad industrial, lo que coincide con la tesis de Ristuccia y Solomou (2014).

${ }^{16}$ Entre 1914 y 1919, el número de operarios casi se duplicó (32k a 60k). En cambio, entre 1938 y 1946 sólo aumentó $50 \%(88 \mathrm{k}$ a $132 \mathrm{k})$. 


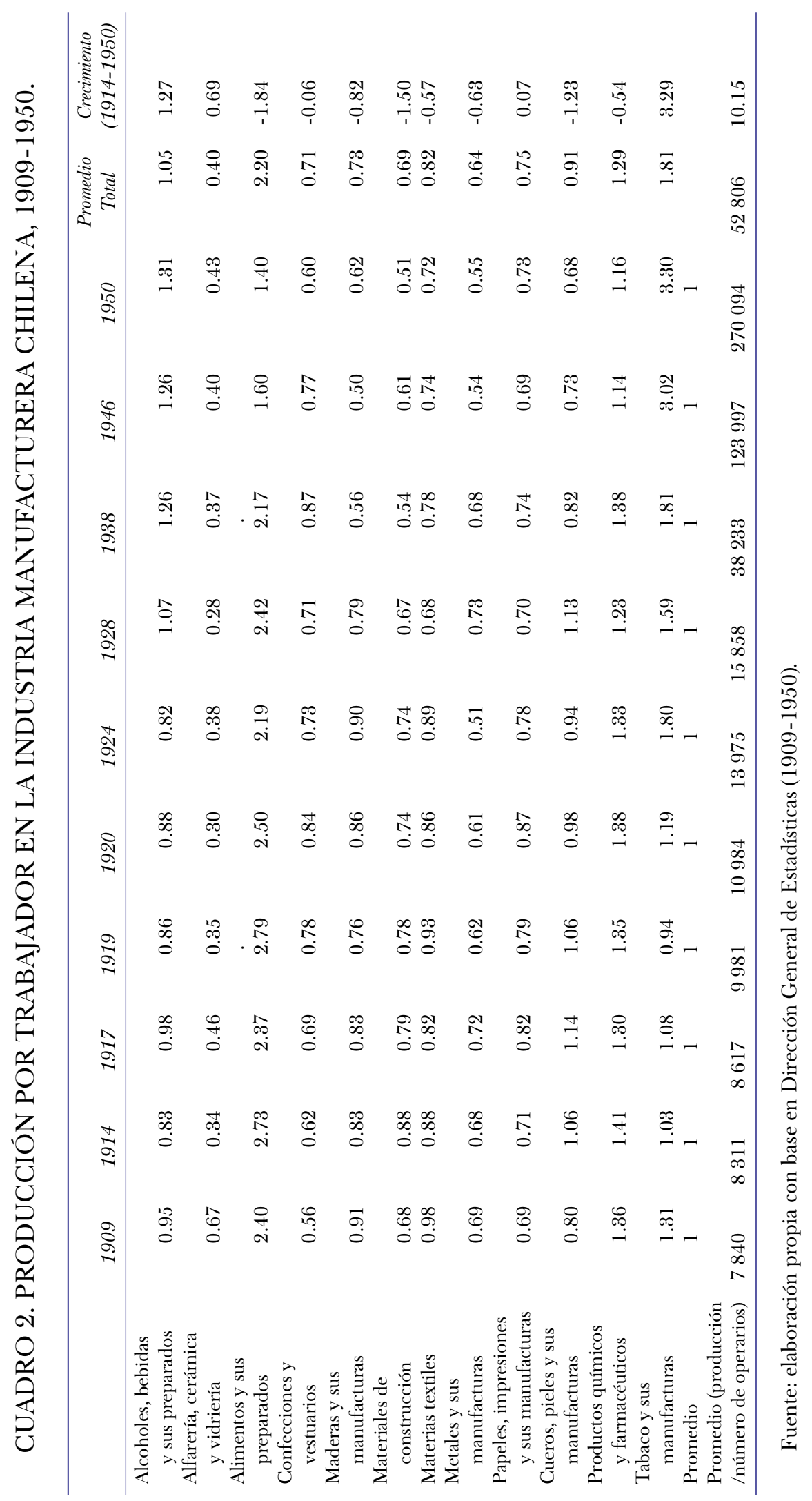


LA ELECTRIFICACIÓN Y PRODUCTIVIDAD INDUSTRIAL SECTORIAL

La composición de la potencia industrial entre 1895 y 1955 distingue entre motores primarios y eléctricos, así como entre los tipos de motores que conforman la potencia primaria (véase cuadro 3). ${ }^{17}$ En 1895, la potencia mecánica de la industria era impulsada completamente por motores primarios. Su fuerza motriz fue mayoritaria en la generación de energía mecánica hasta, al menos, 1928, en que registraron $55 \%$ de la potencia total (medida en cantidad de HP). Desde ese año, su participación relativa en la totalidad de la potencia industrial caería hasta un mínimo de $19.4 \%$ en 1955.

Pese a reducir su participación relativa, en términos absolutos la potencia de los motores primarios creció a $2.9 \%$ al año entre 1909 y 1955, mientras los motores eléctricos lo hicieron a $11.2 \%$ al año. En valores absolutos, la reducción de la potencia total de los motores primarios sólo ocurrió al final del periodo analizado, cuando cayó de 125.426 HP en 1950 a 115.102 HP en 1955. Al contrario, la potencia de los motores eléctricos aumentó de $353.225 \mathrm{HP}$ a $478.906 \mathrm{HP}$ en el mismo tramo. Ambos procesos explican el gran incremento en la electromecanización, que aumentó de $73.8 \%$ a $80.6 \%$ en sólo cinco años.

$\mathrm{El}$ análisis de la composición de la potencia industrial nos permite observar diversas transiciones energéticas ocurriendo en forma simultánea, confirmando que la modernización industrial penetraba entre sectores donde persistía una industria tradicional, que empleaba energías tradicionales y convertidores animados propios de una etapa preindustrial. ${ }^{18}$ De esta forma, mientras en algunas industrias se producía la transición hacia la electrificación, simultáneamente ocurría una transición en la que se sustituían los motores preindustriales por máquinas a vapor. Así, al menos hasta 1928, numerosas industrias con un grado muy avanzado de electrificación convivían con industrias tradicionales. Estos hechos podrían explicar por qué, durante esta primera etapa, se observan menores tasas de crecimiento de la productividad industrial.

En 1924, los motores a vapor suponían la mayor parte de la potencia total de los motores primarios, registrando cifras cercanas a $70 \%$ (véase cuadro 3). Sin embargo, en 1909, los vapores suponían sólo $42.9 \%$, seguidos de cerca por los motores hidráulicos con $38.7 \%$. El uso de hidroenergía en Chile es de larga data, siendo empleado primero bajo la forma de molinos de agua (Lacoste, 2018), y luego bajo la forma de hidroelectricidad. La dotación de recursos hídricos fue destacada desde temprano por la Sofofa. En 1920, los técnicos de la Sofofa señalaron que la disponibilidad de fuerzas hidráulicas, aptas para la generación de hidroelectricidad, era una de las características que hacían prever a Chile como un país industrial (Sofofa, 1920, p. 5). Probablemente, esta primera década del siglo xx evidenció la sustitución de las máquinas hidráulicas por las máquinas a vapor.

${ }^{17}$ Desde 1938, las fuentes omiten la información sobre la composición de los motores primarios.

${ }^{18}$ Este fenómeno también ha sido documentado en las industrias japonesas (Minami, 1977), portuguesa (Teives y Sharp, 2019), y en la industria del hierro y acero suecas (Ducoing y Olsson-Spjut, 2018). 


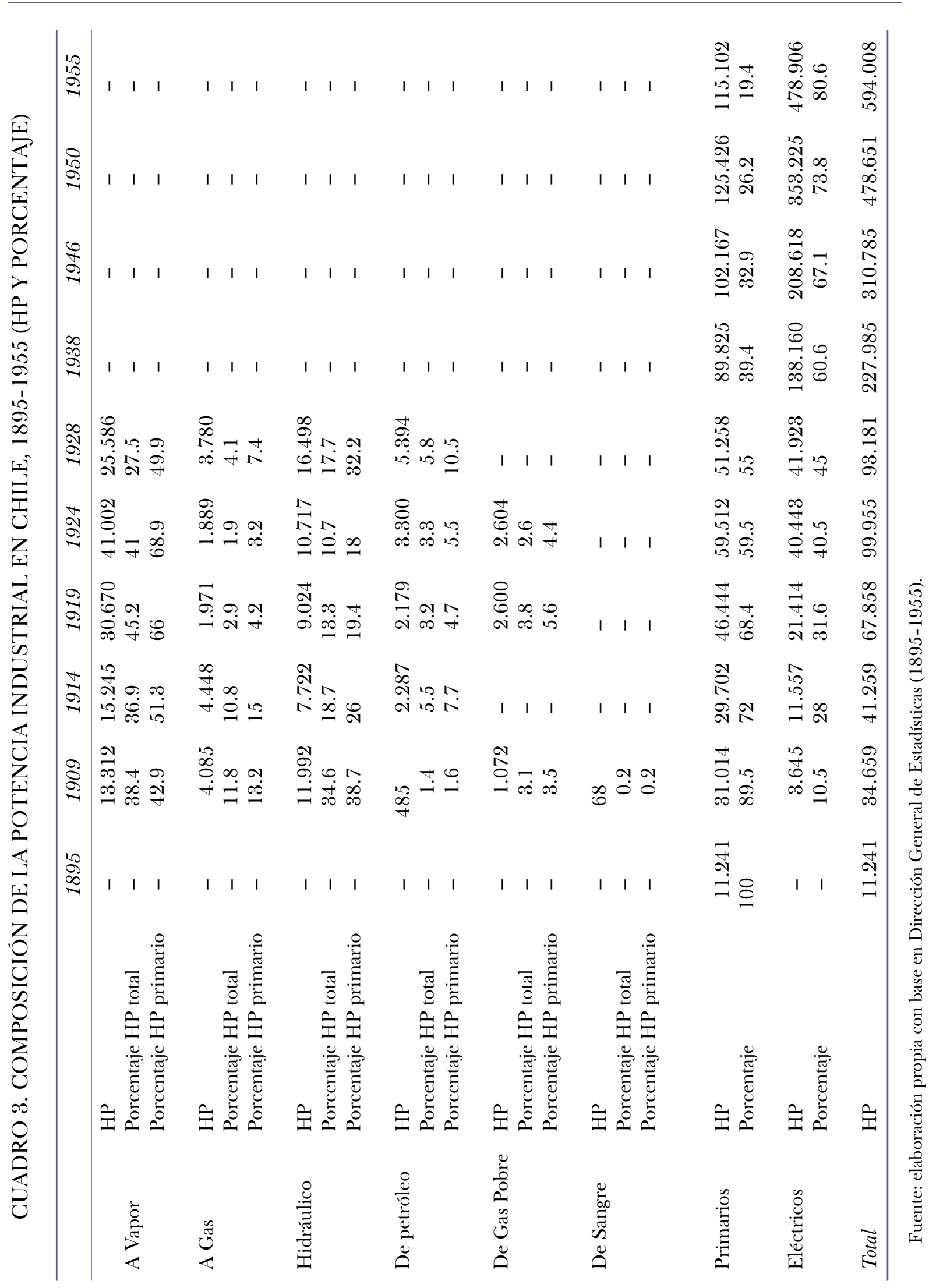


Un ejemplo de la transición desde el uso de motores hidráulicos hacia los motores a vapor, y luego a motores eléctricos es el de la fábrica Bellavista Oveja Tomé. Según López (2012), dicha fábrica data de mediados del siglo xIx, y hasta fines del mismo siglo contó con modernas ruedas hidráulicas que movilizaban las máquinas de tejer y abotonar. Un aspecto destacado de este establecimiento fue su ubicación a la orilla del Estero Bellavista, fuente de donde extraía la energía hidráulica. Sin embargo, en 1896, el establecimiento de elevados aranceles a la importación de bienes manufactureros impulsó la producción de esta industria. La necesidad de incrementar la producción llevó a la modernización de la misma, lo que derivó en la instauración de modernas máquinas a vapor, de las que se utilizaba tanto la energía cinética como el vapor para el lavado y secado de la lana, así como el planchado de las telas. Hacia 1938, la fábrica contaba, además, con una turbina hidráulica Francis, ubicada varios kilómetros lejos de la fábrica, pero que servía para generar energía eléctrica que se transmitía al interior de la fábrica para impulsar los motores eléctricos.

Junto a lo anterior, mientras algunas industrias habían transitado hacia la electrificación, otras aún dependían de la potencia de ruedas hidráulicas, molinos de viento, e incluso motores "de sangre”. Según el Anuario Estadístico de 1909 (Dirección General de Estadísticas, [1909]), durante este año aún encontramos industrias que empleaban motores a "sangre", concentradas en su mayoría en la industria alimenticia. ${ }^{19}$ Estas industrias convivían con otras que presentaban una electrificación avanzada, como la industria de la alfarería, cerámica y vidriería y la industria textil, con una electromecanización de $43 \%$ y $33 \%$, respectivamente. Del mismo modo, según el Anuario Estadístico de 1928 (Dirección General de Estadísticas, [1928]), 8.2 \% de toda la potencia hidráulica empleada en dicho año correspondía a ruedas hidráulicas, concentradas en la industria de los alimentos, particularmente en los molinos. ${ }^{20}$ Este mismo año aún se podían encontrar industrias que empleaban motores de viento, con una potencia total de $70 \mathrm{HP}$, correspondientes a $0.03 \%$ de la potencia total de los motores primarios. Nuevamente, la mayor parte de esta potencia se concentraba en la industria alimenticia, aunque en esta oportunidad en la industria de la sal, con $20 \mathrm{HP}$.

El uso de energías tradicionales en la industria, así como el empleo de convertidores tradicionales y la intensificación del factor trabajo, contrastan con el nivel de modernización del sector minero. Pese a que la minería y metalurgia no están consideradas entre los datos que presentamos en esta investigación, la gran minería chilena había modernizado su producción desde temprano en el siglo xx, situación reflejada en su elevado consumo de petróleo, a la vez que en la elevada generación y consumo de electricidad durante la mayor parte del siglo xx y parte del siglo xxI (Garrido-Lepe, 2018).

La diferencia en los grados de modernización dentro de la industria también se observa en el uso de la potencia de motores a vapor. Según el mismo anuario de 1928, $96.5 \%$ de la potencia de los vapores empleados dicho año correspondía a motores de pistón a vapor (24.685 HP), y sólo el $3.5 \%$ restante a turbinas a vapor $(901 \mathrm{HP})$.

${ }^{19}$ De los 68 HP registrados ese año como “motores de sangre”, 35 HP se empleaban en la industria alimenticia. En 1913 se registran $19 \mathrm{HP}$ en estos motores, de los cuales trece correspondían a la industria de bebidas.

${ }^{20}$ La potencia de las ruedas hidráulicas consistió en $1.345 \mathrm{HP}$, correspondientes a $8.2 \%$ de toda la potencia hidráulica. De ellos, los molinos empleaban 1.002 HP. El 91.8\% restante de la potencia hidráulica corresponde al uso de turbinas hidráulicas, concentradas en la industria de papeles e impresiones, con $7.141 \mathrm{HP}$ (correspondientes a $47 \%$ de la potencia de las turbinas hidráulicas), y la industria de los alimentos, con 5.227 HP (correspondientes a $34 \%$ de la potencia de las turbinas hidráulicas). Esta potencia era empleada por las empresas en la generación de electricidad. 
Las diferencias en la modernización de la potencia industrial fue un tema resaltado en el álbum gráfico de la Sofofa (véase en González y Núñez, 1926). En dicha publicación, se presentó un detallado estudio de las industrias existentes en Chile. En él destacaban el avance de la electrificación en la industria, revelando una serie de establecimientos que utilizaban ampliamente el motor eléctrico. Su defensa por la tecnología eléctrica los llevaba a declarar que el porvenir de la industria de un país va en relación con el desarrollo de la industria eléctrica (González y Núñez, 1926, p. 238). Sin embargo, su estudio también muestra numerosos establecimientos que aprovechaban el uso de la energía hidráulica y del vapor en altas cantidades.

El hecho de que las industrias incrementaran su potencia con base en máquinas a vapor no es, en ningún caso, sinónimo de atraso. La vigencia de las máquinas de vapor era una realidad, así como los incrementos en la eficiencia de sus unidades. ${ }^{21}$ Además, debemos considerar que la producción de carbón en Chile se encontraba en auge, alcanzando máximos históricos tras la reducción de las importaciones de carbón desde Inglaterra y Australia (Garrido-Lepe, 2021; Yáñez y Jofré, 2011). Recurrir a la máquina a vapor era una opción racional, que no suponía un retroceso en la modernización. Sin embargo, el problema se encontraría en los incrementos de eficiencia a largo plazo, disputa de la cual saldrían vencedores los motores eléctricos y los motores a combustión interna.

La combinación de fuentes de energía y de tipos de motores primarios era una realidad incluso después de la segunda guerra mundial. En 1946, la revista Chile Textil publicaba un apartado sobre la modernización de las fábricas de tejidos en Chile. Pese a señalar explícitamente que la mayor parte de la fuerza motriz se realizaba mediante los motores eléctricos, la publicación revelaba la existencia de diversos tipos de fuerza motriz aplicados por las fábricas según era su conveniencia. En este sentido, señalaba que "muchas industrias han obtenido resultados muy satisfactorios con los generadores de vapor empleados, y es posible que su aplicación se extienda" (Revista Chile Textil, 1946, núm. 21, p. 16). Lo mismo señala de los motores diesel. Sobre la transmisión de la potencia, adelanta que los motores individuales terminarán por reemplazar los árboles motrices. Es decir, hasta ese entonces (1946), la transmisión del movimiento mediante ejes y poleas era una realidad existente masivamente en muchas industrias del sector textil. Es más, la publicación expone las dificultades que experimentaban los empresarios al transitar hacia el motor eléctrico. Sobre ello señalan que, en algunos talleres, la aplicación de los primeros motores individuales eléctricos presentó una serie de problemas, permitiendo descubrir que había procesos en que era más ventajoso usar el árbol motriz en vez de la transmisión individual.

Finalmente, resta por preguntarse cuáles fueron los sectores que lideraron la electrificación de la industria chilena. El cuadro 4 presenta la evolución de la electrificación por sector industrial entre 1909 y 1950, junto al porcentaje anual de la potencia de motores primarios de cada sector sobre el total nacional. Los datos muestran que la electrificación no fue homogénea entre los sectores de la industria chilena, del mismo modo en que la productividad presentó diferencias importantes por sector. $\mathrm{Al}$ contrario, fue característico que los sectores que presentaban una menor potencia total se electrificaran primero. De esta forma, en 1914, ocho de los 17 sectores analizados superaban el $30 \%$ de electromecanización, similar al promedio de las industrias japonesas (Minami, 1977). Sin embargo, fueron pocos los sectores que superaron el $50 \%$ antes de la crisis de la

${ }^{21}$ Smil (2010) señala que las máquinas a vapor de aquella época eran mucho más eficientes que los primeros motores a combustión interna. 
gran depresión, lo que muestra las dificultades que existieron para continuar con la modernización durante la década de 1920. Todos ellos se caracterizan por presentar una baja participación de su capacidad motriz en la capacidad total de la industria, con niveles inferiores a $6 \%$ del total de HP.

La relación entre baja participación de la capacidad total y una elevada electromecanización resalta en los casos de la industria del tabaco, las industrias de la alfarería, cerámica y vidriería y, un poco más atrás, la industria de confecciones y vestuarios. En los tres casos, su participación en la capacidad total es virtualmente cero, y su electromecanización superior a $50 \%$ desde muy temprano. Es decir, en estas industrias, las escasas máquinas empleadas eran eléctricas. Todos estos casos, exceptuando la industria del tabaco, se caracterizaron por una reducida productividad.

En cambio, aquellos sectores que contaban con mayor potencia instalada, como las industrias de alcoholes y bebidas, las de alimentos, las industrias de maderas y sus manufacturas, las de materiales textiles, y las de productos químicos, debieron esperar hasta la década de 1930 para superar el $50 \%$ de electromecanización. El sector que presenta la menor electrificación fue la industria de los alimentos, con sólo 60.7 \% en 1950. Al mismo tiempo, este fue el sector que presentó el mayor peso sobre la potencia total de la industria, al menos hasta 1946, y la mayor productividad sectorial hasta 1928.

Aunque la electrificación de la industria pudo no tener efectos inmediatos en la productividad, es probable que sí haya provocado una reducción de las pérdidas del consumo de energía y una reducción de la intensidad energética. Sobre este tema, la revista Chile Textil señalaba que, en 1946, la fuerza motriz de las fábricas textiles era mayoritariamente eléctrica y suministrada por las empresas eléctricas de servicio público. La publicación destaca que estas fábricas dieron preferencia a la electricidad para disminuir las pérdidas de energías que suponía el sistema anterior. Por otro lado, también destacaba las ventajas de poder mantener en funcionamiento o desconectar máquinas individualmente, a diferencia del sistema anterior en que la potencia era distribuida a todas las máquinas (Revista Chile Textil, 1946, núm. 21, pp. 15-17). Fueron justamente dichas ventajas las que detectaron Devine (1983), Schurr (1984) y Ristuccia y Solomou (2014) para la industria estadunidense durante la década de 1920. Como se señala en la revista Chile Textil, es probable que esta situación haya ocurrido en la industria chilena, aunque con un atraso relativo respecto a la industria estadunidense. Sin embargo, esta es una hipótesis que aún está por comprobarse, y que queda para futuras investigaciones.

\section{Conclusiones}

La electrificación de la fuerza motriz fue una etapa clave en la modernización industrial en el mundo. En los actuales países de ingreso alto, la importancia relativa de la potencia de los motores eléctricos sobre la potencia total de la industria habría alcanzado cifras superiores al $80 \%$ poco antes de la segunda guerra mundial. En estos casos, la electrificación industrial describe una tendencia caracterizada por tres fases de crecimiento: lento crecimiento en el inicio de la electrificación, seguida de una segunda fase de crecimiento acelerado, y una tercera fase de estancamiento e incluso decrecimiento al alcanzar cifras entre el $80 \%$ y $90 \%$ de electromecanización. La electrificación industrial chilena, en cambio, sufrió interrupciones e incluso retrocesos durante los conflictos bélicos, alcanzando los niveles de electrificación de los países de ingreso alto con 20 a 25 años de retraso. 


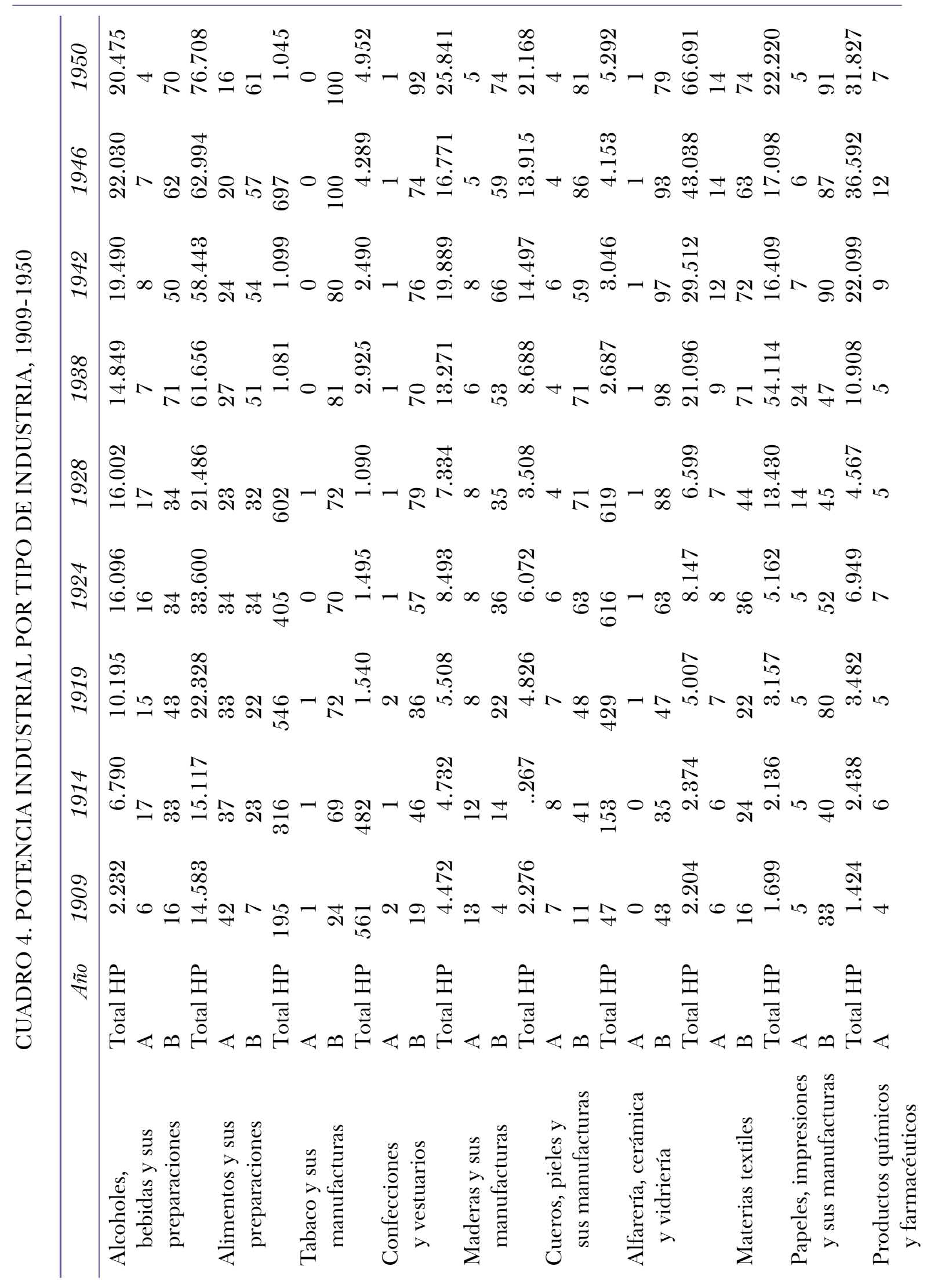




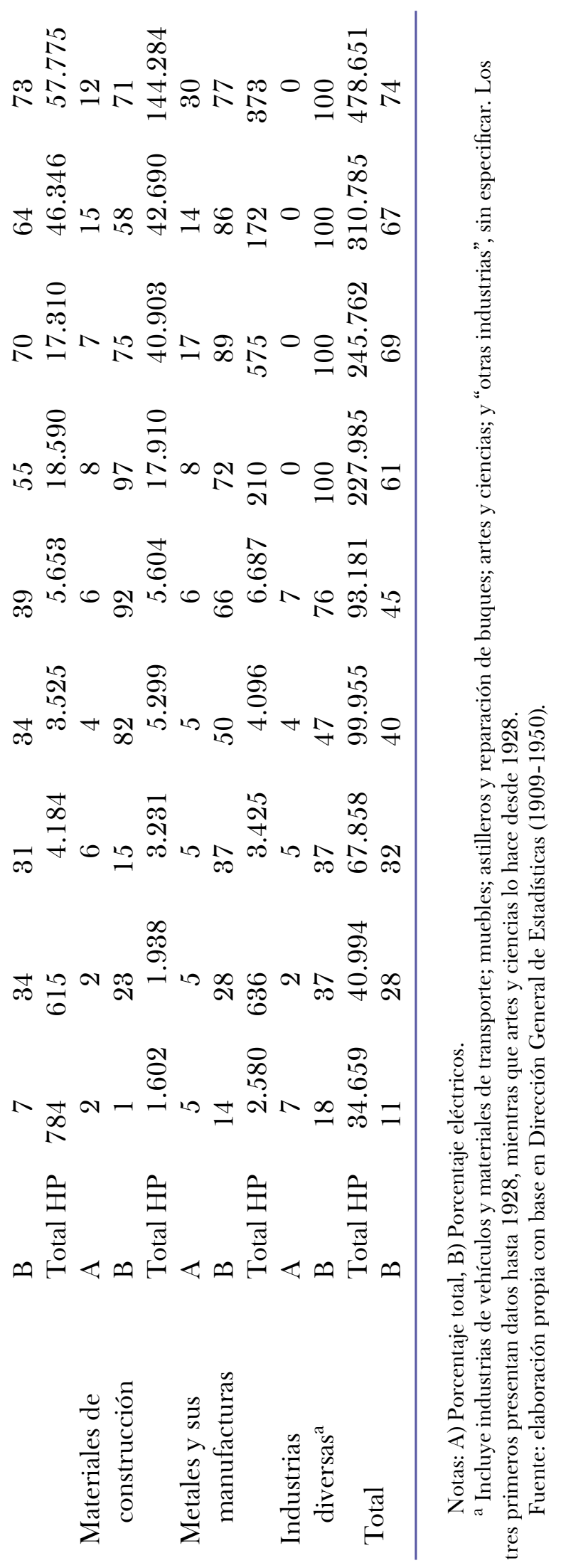


Los datos reunidos para esta investigación indican una escasa relación entre la electrificación industrial y los incrementos de productividad, siendo los más productivos aquellos sectores con menor electrificación. La interrupción de la electrificación pudo haber afectado al crecimiento de la productividad industrial, principalmente durante la primera guerra mundial. Durante este conflicto, las industrias hicieron uso de los recursos que estaban disponibles en su momento, recurriendo incluso a técnicas propias de fases anteriores en la modernización industrial. La necesidad de incrementar la producción llevó al aumento en el uso de motores a vapor, fenómeno que se repite durante la segunda guerra mundial.

Nuestra investigación demuestra que las guerras mundiales implicaron una reducción de las importaciones de bienes de capital, específicamente de la importación de motores. Dicha reducción impidió continuar con el ritmo de electrificación alcanzada antes de la primera guerra mundial. La crisis de la gran depresión, así como la segunda guerra mundial, reprodujeron esta dinámica, impactando negativamente en la importación de motores.

Por último, los datos demuestran que la electrificación industrial en Chile no habría sido homogénea, avanzando primero en aquellos sectores de menor capacidad instalada. Al contrario, se observa una serie de transiciones energéticas ocurriendo en forma simultánea, coexistiendo industrias con modernización destacada junto a establecimientos con tecnología propia de la era preindustrial. En algunos casos, incluso, se recurrió a los molinos de viento y ruedas hidráulicas, retrasando su desaparición hasta fines de la década de 1920. Del mismo modo, en las industrias textiles, el uso de motores primarios y la transmisión mediante ejes y poleas fue una realidad significativa hasta, por lo menos, 1946. En este sentido, la adopción de la nueva tecnología no habría reemplazado a la antigua, sino que la habría complementado. Por esta razón, la electrificación industrial en Chile mostraría un atraso relativo de casi 20 años respecto a las economías de ingreso alto, lo que evidencia las dificultades de la economía chilena para desarrollar procesos de modernización energética.

\section{LISTA DE REFERENCIAS}

Allen, R. (2009). The British industrial revolution in global perspective. Cambridge: Cambridge University Press.

Antolín, F. (1988). Electricidad y crecimiento económico. Los inicios de la electricidad en España. Revista de Historia Económica / Journal of Iberian and Latin American Economic History, 6(3), 635655. DOI: 10.1017/S0212610900000938

Astorga, P., Bergés, A. y Fitzgerald, V. (2011). Productivity growth in Latin América over the long run. Review of Income and Wealth, 57(2), 203-223. Dor: 10.1111/j.1475-4991.2011.00447.x

Badia-Miró, M. y Carreras-Marín, A. (2008). The first world war and coal trade geography in Latin America and the Caribbean, 1890-1930. Jahrbuch für Geschichte Lateinamerikas, 45(1). DoI: $10.7767 /$ jbla.2008.45.1.369

Badia-Miró, M. y Ducoing, C. (2014). The long run development of Chile and the natural resources curse. Linkages, policy and growth, 1850-1950. SSRN Electronic Journal. Dor: 10.2139/ssrn .2539023

Bardini, C. (1997). Without coal in the age of steam: A factor-endowment explanation of the Italian industrial lag before world war I. The Journal of Economic History, 57(3), 633-653. DoI: $10.1017 /$ S0022050700019070 
Bértola, L. (2011). Bolivia (Estado plurinacional de), Chile y Perú desde la Independencia: una historia de conflictos, transformaciones, inercias y desigualdad. En L. Bértola y P. Gerchunoff (eds.), Institucionalidad y desarrollo económico en América Latina (pp. 227-285). Santiago: Comisión Económica para América Latina y el Caribe. Recuperado de http://hdl.handle.net/11362 /3939

Bértola, L. y Ocampo, J. (2010). Desarrollo, vaivenes y desigualdad: Una historia económica de América Latina desde la independencia. Madrid: Secretaría General Iberoamericana. Recuperado de https://dds.cepal.org/redesoc/publicacion?id=2161

Bertoni, R. y Román, C. (2013). Auge y ocaso del carbón mineral en Uruguay. Un análisis histórico desde fines del siglo XIx hasta la actualidad. Revista de Historia Económica/Journal of Iberian and Latin American Economic History, 31(3), 459-497. Dor: 10.1017/S0212610913000207

Betrán, C. (2005). Natural resources, electrification and economic growth from the end of the nineteenth century until world war II. Revista de Historia Económica, 23(1), 47-81.

Bulmer-Thomas, V. (2003). The economic history of Latin America since independence. Londres: University College London.

Bureau Central de Statistique (1936-1950). Annuaire Statistique de la Suède. $23^{a}$ Annèe 1936 e $37^{a}$ Annèe 1950 . Estocolmo: Kungl. Boktryckeriet. P. A. Norstedt \& Söner.

Cabezón, P. (1971). Antecedentes históricos de las importaciones y de la política comercial en Chile. Cuadernos de Economía, 8(25), 1-35.

Cariola, C. y Sunkel, O. (1991). Un siglo de historia económica de Chile: 1830-1930. Santiago: Universitaria.

Census Bureau, U. (1975). Historical statistics of the United States, colonial times to 1970 [Manufactures section] (Bicentennial Edition). Washington: Census Bureau. Recuperado de https://www.cen sus.gov/library/publications/1975/compendia/hist_stats_colonial-1970.html

Comisión Económica para América Latina y el Caribe [CEPAL] (1956). La energía en América Latina. Nueva York: Naciones Unidas.

Corfo [Corporación de Fomento de la Producción] (1939). Fomento de la producción de energía eléctrica. Santiago: Nascimiento.

Couyoumdjian, J., Larroulet, C. y Díaz, D. (2020). Another case of the middle-income trap: Chile, 1900-1939. Revista de Historia Económica / Journal of Iberian and Latin American Economic History, 1-29. Dor: 10.1017/S0212610920000221

David, P. (1990). The dynamo and the computer: An historical perspective on the modern productivity paradox. American Economic Review, 80(2), 355-361.

Devine, W. D. (1983). From shafts to wires: Historical perspective on electrification. The Journal of Economic History, 43(2), 347-372. DOI: 10.1017/S0022050700029673

Dirección General de Estadísticas (Varios años). Anuario Estadístico de la República de Chile. Santiago de Chile: Autor.

Dirección General del Servicio Estadístico Nacional (1947). IV Censo General de la Nación. Censo Industrial de 1946. Buenos Aires: Dirección General de Servicios Técnicos del Estado.

Dirección Nacional de Estadística y Censos (1960). Censo Industrial 1954. Buenas Aires: Autor.

Dominion Bureau of Statistics (1936). The Canada year book 1934-1935. Ottawa: J. O. Patenaude, I. S. O., King's Printer.

Dominion Bureau of Statistics (1946). The Canada year book 1946. Ottawa: Edmond Cloutier, C. M. G., B. A., L. Ph. 
Du Boff, R. (1966). Electrification and capital productivity: A suggest approach. The Review of Economics and Statistics, 48(4), 426-431.

Ducoing, C. (2012). Inversión en maquinaria, productividad del capital y crecimiento económico en el largo plazo. Chile 1830-1938 (Tesis de Doctorado). España, Universidad de Barcelona.

Ducoing, C. y Badia-Miró, M. (2013). El PIB industrial de Chile durante el ciclo del salitre, 18801938. Revista Uruguaya de Historia Económica, 3(3), 11-32.

Ducoing, C. y Olsson-Spjut, F. (2018). The energy transition in the Swedish iron and steel sector, 1800-1939. Lund Papers in Economic History, 182, 1-18.

Durán, X., Musacchio, A. y Della Paolera, G. (2017). Industrial growth in South America. Argentina, Brazil, Chile, and Colombia, 1890-2010. En K. O’Rourke y J. G. Williamson (eds.), The spread of modern industry to the periphery since 1871 (pp. 318-342). Nueva York: Oxford University Press.

Empresa Nacional de Electricidad [ENDESA] (1965). Producción y consumo de energía en Chile. Santiago: Gerencia de Explotación, Endesa.

Empresa Nacional de Electricidad [ENDESA] (1986). Producción y consumo de energía en Chile, 1985. Santiago: Gerencia de Explotación, EndEsa.

Empresa Nacional de Electricidad [ENDESA] (1993). ENDESA: 50 años. Santiago: Lord Cochrane.

Enflo, K., Kander, A. y Schön, L. (2009). Electrification and energy productivity. Ecological Economics, 68(11), 2808-2817.

Ffrench-Davis, R., Muñoz, O., Benavente, J. y Crespi, G. (2003). La industrialización chilena durante el proteccionismo (1940-1982). En E. Cárdenas, J. Ocampo y R. Thorp (eds.), Industrialización y Estado en la América Latina: la leyenda negra de la posguerra (pp. 159-209). México: Fondo de Cultura Económica.

Folchi, M., Blanco-Wells, G. y Meier, S. (2019). Definiciones tecno-políticas en la configuración de la matriz energética chilena durante el siglo xx. Historia (Santiago), 52(2), 373-408. DoI: 10.4067/S0717-71942019000200373

Fouquet, R. (2010). The slow search for solutions: Lessons from historical energy transitions by sector and service. Energy Policy, 38(11), 6586-6596. Dor: 10.1016/j.enpol.2010.06.029

Fouquet, R. (2016). Historical energy transitions: Speed, prices and system transformation. Energy Research E Social Science, 22, 7-12. DoI: 10.1016/j.erss.2016.08.014

Foxley, A. (2012). La trampa del ingreso medio. El desafío de esta década para América Latina. Santiago: CIEPLAN. Recuperado de https://www.cieplan.org/la-trampa-del-ingreso-medio-el-desafio-de -esta-decada-para-america-latina/

Galaz-Mandakovic, D. (2019). Luces yugoslavas para el oscuro puerto de Tocopilla. De la innovación a la obsolescencia (1914-1942). Revista Taltalia, 12, 121-137. DOI: 10.5281/ZENODO.3750465

Garrido-Lepe, M. (2018). El consumo de energía en la minería chilena. 1906-2013. Historia 396, $8(1), 131-161$.

Garrido-Lepe, M. (2021). Los tres ciclos del carbón mineral en Chile, 1844-2014. En C. Yáñez (ed.), La renovada historia económica chilena (pp. 35-52). Valparaíso: Editorial UV. Recuperado de https://editorial.uv.cl/catalogo/academica/356-la-renovada-historia-economica-de-chile

Goldfarb, B. (2005). Diffusion of general-purpose technologies: Understanding patterns in the electrification of US Manufacturing 1880-1930. Industrial and corporate change, 14(5), 745773. DoI: $10.1093 /$ icc/dth068 
Gómez-Galvarriato, A. y Williamson, J. G. (2009). Was it prices, productivity or policy? Latin American industrialisation after 1870. Journal of Latin American Studies, 41(4), 663-694. DoI: 10.1017/S0022216X09990551

González, P. y Núñez, M. (1926). Álbum gráfico e histórico de la Sociedad de Fomento Fabril y de la Industria Nacional. Santiago: Imprenta Cervantes.

Hirschman, A. (1968). The political economy of import-substituting industrialization in Latin America. The Quarterly Journal of Economics, 82(1), pp. 1-32. DoI: 10.2307/1882243

Hofman, A. A. (2000). The economic development of Latin America in the twentieth century. Cheltenham: Edward Elgar.

Instituto de Ingenieros de Chile (1988). Política eléctrica. Santiago: Universitaria.

Instituto de Ingenieros de Chile (2014) [1922]. La Ley general de producción y distribución de energía eléctrica. Anales del Instituto de Ingenieros de Chile, 1, 4-8.

Kander, A., Malanima, P. y Warde, P. (2013). Power to the people: Energy in Europe over the last five centuries. Princeton: Princeton University Press.

Kirsch, H. (1977). Industrial development in a traditional society: The conflict of entrepreneurship and modernization in Chile. Gainesville: University Presses of Florida.

Lacoste, P. (2018). Molinos harineros como espacios biodinámicos en Chile (1569-1841). América Latina en la Historia Económica, 25(3), 103-132. Dor: 10.18232/alhe.907

Landes, D. (1979). Progreso tecnológico y revolución industrial. Madrid: Tecnos.

López, L. (2012). Las maquinarias textiles y el proceso productivo. En A. Cartes, R. Luppi y L. López (eds.), Bellavista Oveja Tomé: una fábrica en el tiempo (pp. 67-83). Concepción: Tramal Impresiones.

Mensaje leído por S. E. Don Arturo Alessandri Palma en la apertura de las sesiones ordinarias del Congreso Nacional $1^{\circ}$ de junio de 1923. (1923). Diarios de Sesiones del Congreso Nacional.

Millward, R. (2005). Private and public enterprise in Europe. Energy, telecommunications and transport, 1830-1990. Cambridge: Cambridge University Press.

Minami, R. (1977). Mechanical power in the industrialization of Japan. The Journal of Economic History, 37(4), 935-958. Dor: 10.1017/S0022050700094754

Muñoz, O. (1968). Crecimiento industrial de Chile, 1914-1965. Santiago: Universidad de Chile.

Myllyntaus, T. (1990). The role of industry in the electrification of Finland. Discussion Papers, 333.

Myllyntaus, T. (1995). Kilowatts at work. Electricity and industrial transformation in the Nordic countries. En A. Kaijser y M. Hedin (eds.), Nordic energy systems: Historical perspectives and current issues (pp. 101-128). Massachusets: Science History Publications.

Nazer, J. y Llorca-Jaña, M. (2020). Chile’s National Electricity Company (EndesA): A successful case of state-led national electrification, ca. 1936-1981. Revista de Historia Industrial. Economía y Empresa, 29(80), 183-222. DoI: 10.1344/rhi.v29i80.30767

O'Connor, P. (2010). Energy transitions. The Frederick S. Pardee Center for the Study of the Longer-Range Future. Recuperado de https://www.bu.edu/pardee/pardee-paper-012-energy

Ortega, L. (1992). El proceso de industrialización en Chile 1850-1930. Historia, 26, 213-246.

Ortega, L. (2012). La crisis de 1914-1924 y el sector fabril. Chile. Historia, 45(2), 433-454.

Oshima, H. (1984). The growth of U.S. factor productivity: The significance of new technologies in the early decades of the twentieth century. The Journal of Economic History, 44(1), 161-170. DOI: $10.1017 / \mathrm{S} 0022050700031429$

Palma, J. (1984). Chile 1914-1935: de economía exportadora a sustituidora de importaciones. Santiago: CIEPLAN. Recuperado de http://www.memoriachilena.gob.cl/602/w3-article-71087.html 
República de Argentina (1917). Tercer Censo Nacional de La República Argentina. Buenos Aires: Talleres gráficos de L. J. Rosso y Cía.

Ristuccia, C. y Solomou, S. (2014). Can general purpose technology theory explain economic growth? Electrical power as a case study. European Review of Economic History, 18(3), 227-247. DOI: $10.1093 / \mathrm{ereh} / \mathrm{heu} 008$

Rubio, M. del M. (2019). The first world war and the Latin American transition from coal to petroleum. Environmental Innovation and Societal Transitions, 32, 45-54. DoI: 10.1016/j.eist.2018. 03.002

Rubio, M. del M., y Folchi, M. (2012). Will small energy consumers be faster in transition? Evidence from the early shift from coal to oil in Latin America. Energy Policy, 50, 50-61. DoI: 10.1016/j.enpol.2012.03.054

Rubio, M. del M., Yáñez, C., Folchi, M. y Carreras, A. (2009). Energy as an indicator of modernization in Latin America, 1890-1925: Energy in Latin America. The Economic History Review, 63(3), 769-804. DOI: 10.1111/j.1468-0289.2009.00463.x

Schön, L. (2000). Electricity, technological change and productivity in Swedish industry, 18901990. European Review of Economic History, 4(2), 175-194. Dor: 10.1017/S1361491600000046

Schurr, S. H. (1984). Energy use, technological change, and productive efficiency: An economichistorical interpretation. Annual Review of Energy, 9(1), 409-425. Dor: 10.1146/annurev.eg.09 .110184 .002205

Smil, V. (2010). Energy transitions: History, requirements, prospects. Santa Bárbara: Praeger.

Smil, V. (2004). World history and energy. En Encyclopedia of energy (pp. 549-561). Elsevier. Dor: 10.1016/B0-12-176480-X/00025-5

Sofofa [Sociedad de Fomento Fabril] (1895). Boletín de la Estadística Industrial de la República de Chile 1894-1895. Santiago: Sociedad de Fomento Fabril.

Sofofa [Sociedad de Fomento Fabril] (1901). Boletín de la Sociedad de Fomento Fabril, 18(6).

Sofofa [Sociedad de Fomento Fabril] (1920). Chile. Breves noticias de sus industrias. Santiago: Sociedad Imprenta i Lotografía Universo.

Sudrià, C. (1994). Un factor determinante: la energía. En J. Maluquer de Motes Bernet (ed.), La economía española en perspectiva histórica: Siglos XVIII-XXI. Barcelona: Áriel.

Sunkel, O. (2011). El presente como historia: Dos siglos de cambio y frustración en Chile. Santiago: Catalonia.

Tafunell, X. (2011). La revolución eléctrica en América Latina: una reconstrucción cuantitativa del proceso de electrificación hasta 1930: The electric revolution in Latin America: A quantitative approach to the electrification process until 1930. Revista de Historia Económica / Journal of Iberian and Latin American Economic History, 29(3), 327-359. Dor: 10.1017/S0212610911000140

Teives, S. y Sharp, P. (2019). Without coal in the age of steam and dams in the age of electricity: An explanation for the failure of Portugal to industrialize before the second world war (EHES Working Paper, 148). European Historical Economics Society.

US. Bureau of the Census (1975). Historical statistics of the United States, colonial times to 1970. Washington, D. C.

Veneros, D. y Ortega, L. (2011). Trabajo femenino fabril en un contexto de modernización: una visión de su evolución por provincias. Chile, 1910-1930. Universum (Talca), 26(1), 151-168. DOI: $10.4067 / \mathrm{S} 0718-23762011000100010$ 
Venneslan, C. (2009). Electrification and industrialisation: An assessment of the industrial breakthrough in Norway. Scandinavian Economic History Review, 57(2), 124-155. Dor: 10.1080/03585 520902799638

Vergara-Montt, E. (1895). Valor mecánico i económico de la electricidad en los usos i necesidades de la industria. Anales del Instituto de Ingenieros de Chile, (57), 191-285.

Woolf, A. (1984). Electricity, productivity, and labor saving: American manufacturing, 19001929. Explorations in Economic History, 21(2), 176-191. DoI: 10.1016/0014-4983(84)90024$\mathrm{X}$

Wrigley, E. (1993). Cambio, continuidad y azar: carácter de la revolución industrial inglesa. Barcelona: Crítica.

Yáñez, C. (2017a). El arranque del sector eléctrico chileno. Un enfoque desde las Empresas de Generación, 1897-1931. En M. Llorca-Jaña y D. Barria (eds.), Empresas y empresarios en la historia de Chile (pp. 175-193). Santiago: Universitaria.

Yáñez, C. (2017b). La intervención del Estado en el sector eléctrico chileno. Los inicios de la empresa pública monopólica. En M. Llorca-Jaña y D. Barria (eds.), Empresas y empresarios en la historia de Chile (pp. 109-131). Santiago: Universitaria.

Yáñez, C. (2019). Electricity generation and electric power in Chile before 1975. En M. LlorcaJaña, R. Miller y D. Barria (eds.), Capitalists, business and state-building in Chile (pp. 217-242). Londres: Palgrave Macmillan.

Yáñez, C. y Garrido-Lepe, M. (2015). El consumo de carbón en Chile entre 1933-1960. Transición energética y cambio estructural. Revista Uruguaya de Historia Económica, 5(8), 76-95.

Yáñez, C. y Jofré, J. (2011). Modernización económica y consumo energético en Chile, 18441930. Historia 396, 1(1), 127-166.

Yáñez, G., Rubio, M. d. M., Jofré, J. y Carreras, A. (2013). El consumo aparente de carbón mineral en América Latina, 1841-2000. Una historia de progreso y frustración. Revista de Historia Industrial, 53, 25-77. 